See discussions, stats, and author profiles for this publication at: https://www.researchgate.net/publication/323617674

\title{
Control of Modular Multilevel Converters Using an Overlapping Multi- Hexagon Space Vector Modulation Scheme
}

Article $\cdot$ March 2018

DOI: 10.1109/JESTPE.2018.2812865

\section{CITATIONS}

4 authors, including:

Oghenewvogaga Oghorada

Landmark University

12 PUBLICATIONS 38 CITATIONS

SEE PROFILE

Some of the authors of this publication are also working on these related projects:
READS

16

Project The Use of Modular Multilevel Cascaded Converters as STATCOM and APC in Distribution Systems View project 


\section{UNIVERSITY OF LEEDS}

This is a repository copy of Control of Modular Multilevel Converters Using an Overlapping Multi-Hexagon Space Vector Modulation Scheme.

White Rose Research Online URL for this paper:

http://eprints.whiterose.ac.uk/128594/

Version: Accepted Version

\section{Article:}

Oghorada, OJK, Zhang, L, Efika, IB et al. (1 more author) (2018) Control of Modular Multilevel Converters Using an Overlapping Multi-Hexagon Space Vector Modulation Scheme. IEEE Journal of Emerging and Selected Topics in Power Electronics. ISSN 2168-6777

https://doi.org/10.1109/JESTPE.2018.2812865

(C) 2018, IEEE. This is an author produced version of a paper published in IEEE Journal of Emerging and Selected Topics in Power Electronics. Personal use of this material is permitted. Permission from IEEE must be obtained for all other uses, in any current or future media, including reprinting/republishing this material for advertising or promotional purposes, creating new collective works, for resale or redistribution to servers or lists, or reuse of any copyrighted component of this work in other works. Uploaded in accordance with the publisher's self-archiving policy.

\section{Reuse}

Items deposited in White Rose Research Online are protected by copyright, with all rights reserved unless indicated otherwise. They may be downloaded and/or printed for private study, or other acts as permitted by national copyright laws. The publisher or other rights holders may allow further reproduction and re-use of the full text version. This is indicated by the licence information on the White Rose Research Online record for the item.

\section{Takedown}

If you consider content in White Rose Research Online to be in breach of UK law, please notify us by emailing eprints@whiterose.ac.uk including the URL of the record and the reason for the withdrawal request. 


\title{
Control of Modular Multilevel Converters Using an Overlapping Multi- Hexagon Space Vector Modulation Scheme
}

\author{
O.J.K. Oghorada, Li Zhang, Ikenna Bruce Efika, C.J. Nwobu \\ *School of Electronic and Electrical Engineering, University of Leeds, United Kingdom, \\ oghorada.oghenewvogaga@lmu.edu.ng,l.zhang@leeds.ac.uk
}

\begin{abstract}
Adapting the conventional Space Vector modulation (SVM) scheme for modular multilevel cascaded converters is complicated as the number of switching vectors increases with the number of voltage levels. This paper introduces a novel SVM scheme that can be applied for the control of modular multilevel cascade converters (MMCC) with any number of levels. Instead of extending a single hexagon to the regions corresponding to the number of levels, the proposed method treats the three-phase MMCC as multiple inverters with a phase limb being a chain of basic three level H-bridge, five-level flying capacitor, or neutral point clamped inverters. Basic two or three level hexagons can be applied to determine the switch states and duty cycles separately within one tier of the converter and many such hexagons can be overlapped, with phase shift relative to each other, for the control of a complete MMCC. This approach simplifies the modulation algorithm and brings flexibility in shaping the output voltage waveforms for different applications. Simulation results confirm the good waveform performance of this scheme. An experimental 5-level MMCC, with a total of six H-bridges as the basic modules, is presented to validate the advantageous features of the method.
\end{abstract}

Key words: Modular Multilevel Cascade Converters, Space Vector Modulation

\section{INTRODUCTION}

Recent development in power converters for high voltage transmission and distribution systems has led to widespread interest in modular multilevel cascaded converters (MMCC) [1-6]. Well-established multilevel converter topologies, such as the neutral point clamped (NPC) and flying capacitor (FC) forms, all present different problems when more levels are added to serve higher voltage applications. For example a 5-level NPC has difficulty in maintaining neutral-point voltage balance and has unequal device loss distributions due to series connected neutral point clamping diodes [7]. These problems are exacerbated when an NPC structure is extended to more than 3 levels [8] and thus it is most suitable for medium voltage applications $(2.3-6.6 \mathrm{kV})$. The FC converter, on the other hand, works well for lower numbers of levels, but when the number of clamping capacitors is increased to raise output voltage, the capacitor voltages become difficult to balance, causing poor output voltage waveform performance and unequal device voltage stress. The classical cascaded H-bridge converter (CHB), using three level full-bridges (3L-FB) as the basic modules in a series chain configuration, can overcome these 
shortcomings. The CHB has led to the development of the MMCC [9-11], which has the favorable features of being modular, hence easy to scale up the voltage level, and having voltage waveforms with very low harmonic contents. The very simple cell structure also reduces the manufacturing costs. The MMCCs have gained attention from industry, having applications in grid-connected converters, STATCOM, HVDC transmission systems and medium voltage drives [12].

The choice of module topology for an MMCC depends on the type of functionality required from the converter. For example, two level half bridge (2L-HB) modules are popular for dc-ac three-phase converters in HVDC applications [13-15]. For a STATCOM 3L-FB is required which allows four quadrant power flow operation. Besides these two types, current developments in MMCC topologies also consider other structures, particularly the 5-level NPC (5L-NPC) and 5-level FC (5L-FC) types [13, 16-19] and their hybrid combinations. The advantages of these 5-level modules are that they offer more switching states and voltage levels per module, hence with the same number of modules as when using $3 \mathrm{~L}-\mathrm{FBs}$, the converter output voltage is higher and harmonic performance is better.

An inherent challenge for MMCCs, regardless of the type of modules used, is the increasing complexity of modulation control due to the number of discrete output voltage levels being extended by cascading more modules. Generally, the well-known selective harmonic elimination technique (SHE) [20-23] or staircase modulation is applied, allowing terminal voltage waveforms with very low harmonic contents when the number of modules is in the range of many tens. However, the method is cumbersome for MMCCs with high number of modules since switching angles need to be accurately estimated for different operating conditions. Computation can be more problematic for applications requiring fast dynamic control like STATCOM and machine drives. Currently the widely used methods for classical and modular multilevel converters are forms of sine-triangle-based PWM, such as level-shifting PWM and phase-shifting PWM, for their simplicity and good waveform performance [24-27].

The Space Vector Modulation (SVM) scheme offers attractive features and both two and three-dimensional versions are widely known and applied [28-35]. However, for an MMCC having many voltage levels per phase, using conventional SVM technique, the number of switching states escalates, and on-line switching vector selection and duty cycle calculation become complicated [36-38]. Various types of SVM methods have been proposed [39-42] over recent decade to simplify the procedure for classical multilevel and modular multilevel cascaded converters. A common approach involves decomposing the space vector diagram into multiples of twolevel or three-level hexagons [28-30]. For example a three-level space vector plane is divided into six two-level hexagons and by noting the position of the reference voltage vector, the appropriate two-level hexagon and 
corresponding switching vectors can be determined. Calculation of selected vector duty cycle and selection of switching states can then be carried out as in a two level inverter. Extension of this approach to five-level space vector plane has also been attempted, and meanwhile optimal switching sequence for achieving good harmonic performance and capacitor voltage balance has been proposed [31-34]. The main problem with the space vector plane division approach lies in the use of lookup tables for generating the gate pulses for the switching devices. As the number of inverter levels increase, there will be an increase in the number of lookup tables as well as their size. Another approach relies on an algorithm-based technique which makes use of a $60^{\circ}$-spaced $g h$ coordinate system to perform the SVM of a multilevel inverter [38]. SVM technique has also been applied for HVDC MMC [39] and switching scheme for the optimized control performance in terms of capacitor voltage balancing, circulating current suppression and common-mode voltage reduction has been developed.

This paper presents a novel overlapping hexagon space vector modulation (OH-SVM) technique mainly for the control of modular multilevel cascaded converters with full-H bridge and full FC-bridge as sub-modules. The rationale of the proposed method bears similarity to the aforementioned space vector division approaches, namely it also uses multiple of either two-level hexagons or three-level hexagons. However, instead of dividing a multilevel space vector plane into many hexagons, the proposed method treats each voltage level of the three phase limbs as an entity whose switching states are covered by a two-level hexagon. This can be extended to three-level hexagons to control MMCC with 5L-FC or 5L-NPC as sub-modules. By overlapping these hexagons for multiple voltage levels, the switching state selection and duty ratio calculation can be performed per hexagon and per module without involving complicated procedures as are needed when using a single multilevel hexagon in the conventional SVM. This scheme offers simplicity and flexibility for controlling MMCCs having any number of chained modules and can give good voltage waveform performance at low switching frequency. The paper also covers an optimal switching sequence selection scheme for the case when three-level hexagon is used for floating capacitor voltage balance and reduction of switching transitions.

The paper is organized as follows: Section II presents a review of five different types of modules used to build modular multilevel converters. Two of these are used for exploring the proposed SVM scheme. In Section III, a brief review of the Multilevel SVM is presented. In Section IV, the principle and analysis of the methods are described. Results of simulation studies are given in Section V. An experimental rig of a six module MMCC with 3L-FB modules built to verify the new SVM method is described in Section VI together with the results obtained. 


\section{MMCCS WITH DIFFERENT CONVERTER TOPOLOGIES}

An MMCC is constructed by chaining a set of converter cells/modules. One such chain forms a converter phase limb and three limbs in star or delta connection constitute a dc-ac converter, also named single star or delta MMCC [43], and can be used for STATCOM or machine drive applications. For HVDC application two such chains are linked in series to form a converter phase limb, one being connected to the positive dc rail and the other to the negative. The ac terminal is at the junction of the chains, and with three such phase limbs, a double star configuration is formed [43]. In this work only the single star/delta connected MMCCs are considered. The main distinguishing feature of each different MMCC structure is the type of module used. Various module concepts exist in literature $[13,17,44,45]$. Fig.1. shows a single star MMCC in which five different types of modules can be used, namely 3L-FB, 5L-FC, 5L-NPC, 5-level FC plus half bridge (5L-FC-H) and, 5-level NPC plus half bridge (5L-NPC-H).

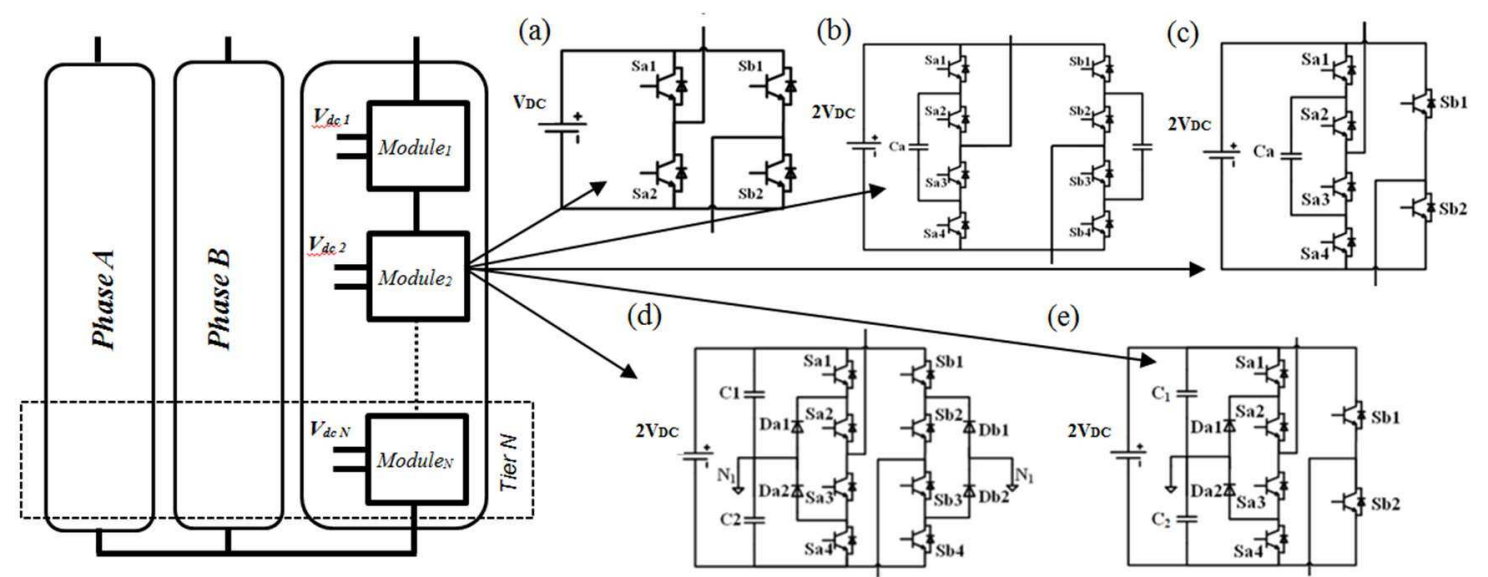

Fig.1. MMCC in star connection with different module structure (a) 3L-FB module (b) 5L-FC module (c) 5L- FC-H module (d) $5 \mathrm{~L}-\mathrm{NPC}$ module (e) $5 \mathrm{~L}-\mathrm{NPC}-\mathrm{H}$ module

\section{ReVIEW OF CLASSiCAL MultileVEL SVM TECHNiQUe}

The SVM technique developed originally for three-phase two-level voltage source inverters offers advantages of easy implementation. It also provides a $15.5 \%$ higher DC link voltage utilization when compared with sinetriangle-based PWM scheme [28]. Extending this to control multilevel inverters [31] leads to an increased number of switching vectors. For example, a multilevel converter comprising four cascaded half-bridge cells per phase has 9 voltage levels ( $-\mathrm{V}_{\max }$ to $\mathrm{V}_{\max }$ through 0 ) and 125 switching state vectors. The overall vector boundary still forms a hexagonal as shown in Fig.3 (a), with vertices being the full voltage in each phase. For choosing the switching states for this converter and calculating their corresponding duty ratios, the position of the reference voltage vector $\vec{V}_{\text {ref }}$ at every sample time instant has to be located. This can be difficult due to the extended hexagon. One method is to divide each of the six hexagon sectors into multiple equal triangles, and check whether each triangle encircles the tip of $\vec{V}_{\text {ref }}$. Naturally as the number of voltage levels increases, the numbers of both the 
switching state vectors and triangle sections increase. For the example 4-cell, 5-level converter it has in total 16 triangles in one of 6 hexagon sectors as shown in Fig. 3(b) and 96 in total for the whole hexagon. In general, if $n$ is the number of voltage levels (from 0 to $+\mathrm{V}_{\max }$ or 0 to $-\mathrm{V}_{\max }$ including 0 volt level) per phase limb, the total numbers of triangular regions, $n_{T}$, is

$$
n_{\mathrm{T}}=6(n-1)^{2}
$$

and the number of switching states, $n_{V}$, required to synthesize a reference voltage for the converter structure shown in Fig. 3 is $n^{3}$. Consequently the modulation process, involving region determination, switching vector selection and subsequent duty cycle calculation, becomes complicated. This can be even more cumbersome for controlling an MMCC. For example a three-phase 9-level FC-MMCC, as shown in Fig. 2, has two cascaded full-bridge FC converter modules per phase limb, so it is regarded as two voltage tiers. Each phase limb's left-hand-side (LHS) half-bridge $\mathrm{FCs}, \mathrm{A}_{1}, \mathrm{~B}_{1}$ and $\mathrm{C}_{1}$, form a three-phase 5-level converter which has 125 switching state vectors. This is the same to the RHS half-bridge FCs $A_{2}, B_{2}$ and $C_{2}$. For the control of both LHS and RHS converters using the conventional multilevel SVM scheme described above, a 5-level hexagon should have two reference voltage vectors $\vec{V}_{\text {ref }}$ and $-\vec{V}_{\text {ref }}$ that are anti-phase to each other as shown in Fig. 3(a), These may lie initially (when $t=0$ ) in sectors 5 and 2 respectively. Table I shows the small triangular regions the reference voltage vector may be in corresponding to the modulation index range from 0.25 to 1 . Table II highlights the conditions used in determining the specific triangle region according to the voltage vector's corresponding $\alpha-\beta$ component magnitudes as defined in equations (6)-(7). Clearly the whole process is more complicated than when controlling the classical multilevel converters such as a 5-level NPC.

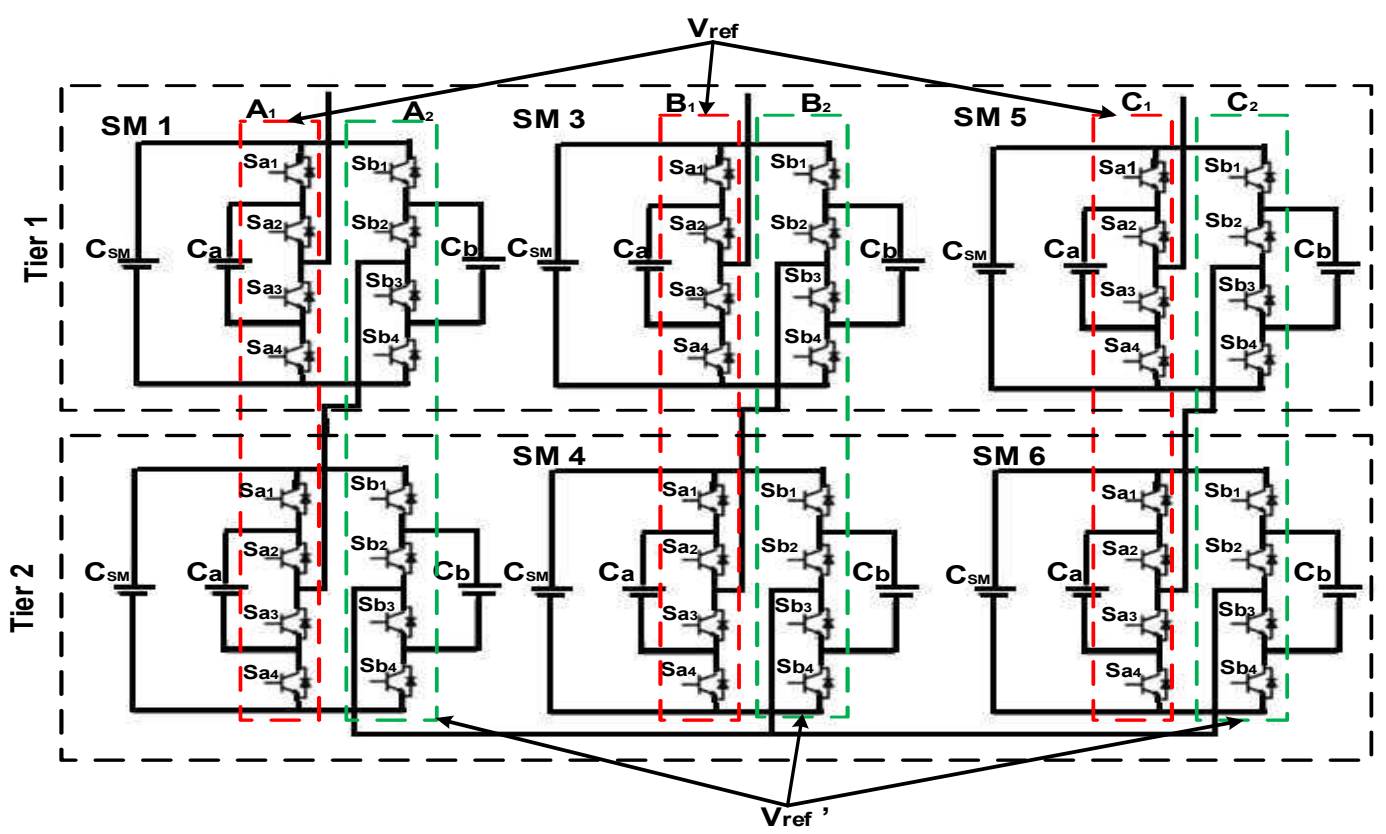

Fig.2. 5-level hexagon SVM implementation on two cascaded 5-Level FCC. 
Table I: Region selection based on $m_{a}=V_{r e f} / V_{d c}$

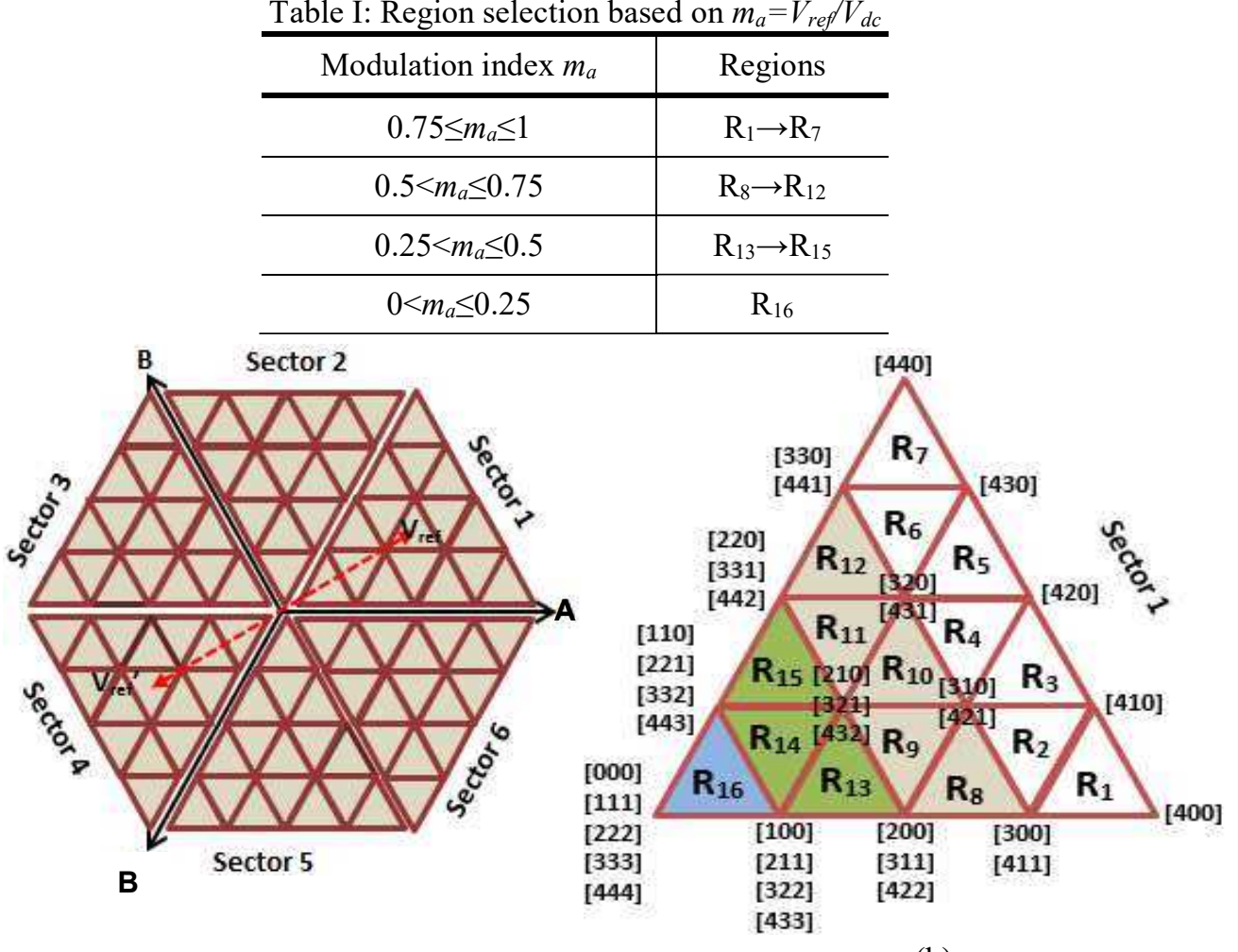

(a)

(b)

Fig.3. Conventional Multilevel-SVM (a) Hexagon for a 5-level SVM and (b) Sector 1 of the 5-level hexagon.

Table II: Selection criteria for regions $\mathrm{R}_{1} \rightarrow \mathrm{R}_{7}$

\begin{tabular}{c|c}
\hline Criteria & Regions \\
\hline $\mathrm{Vs} \alpha>0.75, \mathrm{~V}_{\mathrm{S} \beta}<0.25$ & $\mathrm{R}_{1}$ \\
\hline $0.5<\mathrm{Vs} \alpha<0.75, \mathrm{~V}_{\mathrm{S} \beta}<0.25, \mathrm{Vs} \alpha+\mathrm{V}_{\mathrm{S} \beta}>0.75$ & $\mathrm{R}_{2}$ \\
\hline $0.5<\mathrm{Vs} \alpha<0.75,0.25<\mathrm{V}_{\mathrm{S} \beta}<0.5$ & $\mathrm{R}_{3}$ \\
\hline $0.25<\mathrm{Vs} \alpha<0.5,0.25<\mathrm{V}_{\mathrm{S} \beta}<0.5$ & $\mathrm{R}_{4}$ \\
\hline $0.25<\mathrm{Vs} \alpha<0.5,0.5<\mathrm{V}_{\mathrm{S} \beta}<0.75$ & $\mathrm{R}_{5}$ \\
\hline $\mathrm{V}_{\mathrm{s} \alpha}<0.25,0.5<\mathrm{V}_{\mathrm{S} \beta}<0.75, \mathrm{~V}_{\mathrm{s} \alpha}+\mathrm{V}_{\mathrm{S} \beta}<0.75$ & $\mathrm{R}_{6}$ \\
\hline $\mathrm{Vs} \alpha<0.25, \mathrm{~V}_{\mathrm{S} \beta}>0.75$ & $\mathrm{R}_{7}$ \\
\hline
\end{tabular}

\section{Overlapping Multi-Hexagon Space Vector Modulation (OH-SVM)}

This new space vector modulation scheme simplifies the modulation procedure greatly for MMCCs. There are two implementation methods depending on the type of hexagons used.

\section{A. OH-SVM using Two-level Hexagons}

This is particularly suitable for MMCCs comprising 3-L FB as sub-modules. It uses multiple two-level hexagons. Each of them defines the switching states of all 3L-FB sub-modules in one tier of an MMCC as seen in Fig.4. As mentioned before each full H-bridge sub-module consists of two 2-level half-bridges, there are six of them in a tier, forming two three-phase two-level inverters, LHS and RHS ones. While the LHS one synthesizes a reference 
voltage vector $\vec{V}_{\text {ref }}$, the RHS one synthesizes its $180^{\circ}$ counterpart $\vec{V}_{\text {ref }}$ ', both are in one two-level hexagon for determining the switching states of all switches in one tier. For an MMCC of 3L-FB having four cascaded tiers and generating 9-level voltage, a total of 4 hexagons are required which are projected on one pair of $\alpha-\beta$ axes as shown in Fig.5.

The two-level hexagon OH-SVM can also be used for MMCC of 5L-FC modules as shown in Fig.2. Though in this case there are only two tiers, in total four hexagons are still needed, two for each tier. These hexagons are projected on the same $\alpha-\beta$ axes and are phase shifted from each other by an angle $\alpha_{S H}$ determined by the fundamental reference signal period $T$, and sample period, $T_{S}$, and the number of complementary switches per phase limb $n_{m p}$, as[19]:

$$
\alpha_{\mathrm{SH}}=\frac{\left(T_{S} / 2 n_{m p}\right)}{T} \times 2 \pi .
$$

Assuming the ratio of the sampling period to the fundamental period is $1 / 5$, equation (3) gives the phase shift between each overlapping hexagons $\left(360^{\circ} / 8\right) / 5=9^{\circ}$, resulting in a 2-D representation that contains four interleaved hexagons. It is worth noting that each sub-module consists of two either 2-level half-bridge or 3-level FC halfbridges, hence there are six in total in a tier.

Since each hexagon is phase shifted by $\alpha_{S H}$ radians relative to the next tier below, the angular values of both $\vec{V}_{\text {ref }}$ and $\vec{V}_{\text {ref }}$ in the relevant hexagon are determined by their angles in the $1^{\text {st }}$ hexagon for lowest voltage tier plus a multiple of the phase shift $\alpha_{\mathrm{SH}}$. Both voltages are time varying sinusoidal functions, thus if the phase angle for $\vec{V}_{\text {ref }}$ in the hexagon for the $1^{\text {st }}$ voltage tier at time $t$ is $\theta(t)$ rad., that for the $m^{\text {th }}$ tier at the same time instant is calculated as:

$$
\theta_{m}(t)=\left(\theta(t)+(m-1) \alpha_{S H}\right) \mathrm{rad},
$$

and the corresponding $\vec{V}_{\text {ref }}$ ' is displaced by $180^{\circ}$ from $\theta_{m}$.

Implementation of OH-SVM involves, firstly, determinations of exact locations of $\vec{V}_{\text {ref }}$ and $\vec{V}_{\text {ref }}$ 'in each hexagon, hence the switching states to be applied to sub-module switches of each tier. This requires identifying the sector number, according to the reference voltage vector phase angle $\theta_{m}(t)$ from equation (4), at every sample time instant in a 2-level hexagon. With multiple overlapped hexagons the sector numbers of the reference voltage vectors in each hexagon are different at certain sample instants. This can be obtained from the expression in (5) below which 
shows the Euclidean division of the perceived angle $\left(\theta_{m}\right)$ by the sector angle $\left(60^{\circ}\right.$ or $\left.\pi / 3\right)$, where $S_{N}$ represents the current sector number.

$$
\theta_{m}(t) /(\pi / 3)=\left(S_{N}-1\right) \pi / 3+\theta_{m} \bmod \pi / 3 .
$$

According to magnitudes and angles of $\vec{V}_{\text {ref }}$ and $\vec{V}_{\text {ref }}$ ' the switching vectors for these modules and their respective duty ratios at each sample instant can be calculated by applying the well-known two-level SVM technique as discussed in [46]. Clearly the use of multiple two-level hexagons simplifies the modulation algorithm as compared to using one 5-level hexagons; since each of the two-level hexagons comprises only 8 switching states, there are no multiple triangular regions, hence no need to find which one of the sixteen triangles, as in the 5-level case, containing the reference vectors $\vec{V}_{\text {ref }}$ and $\vec{V}_{\text {ref }}$ '.

It is important to note that by overlapping the hexagons, the method gives equal switching pattern and switch utilization for modules at different voltage levels in one phase-leg. Analogous to multilevel sine-triangle phaseshift PWM scheme [27] with each carrier wave shifted in time, this ensures the floating capacitors of sub-modules in the same phase leg being charged and discharged evenly hence their voltages are balanced at the steady-state.

Fig.6 shows the flowchart for implementing the OH-SVM using 2-level hexagons. The control variables are initialized by first computing the overlapping angle between the hexagons. The $\alpha_{S H}$ aids in the determination of the sectors in which the reference voltage vectors lie in each hexagon. Once the sector is identified, the dwell times of the three closest voltage vectors are calculated and applied to control the converter switches of corresponding tier.

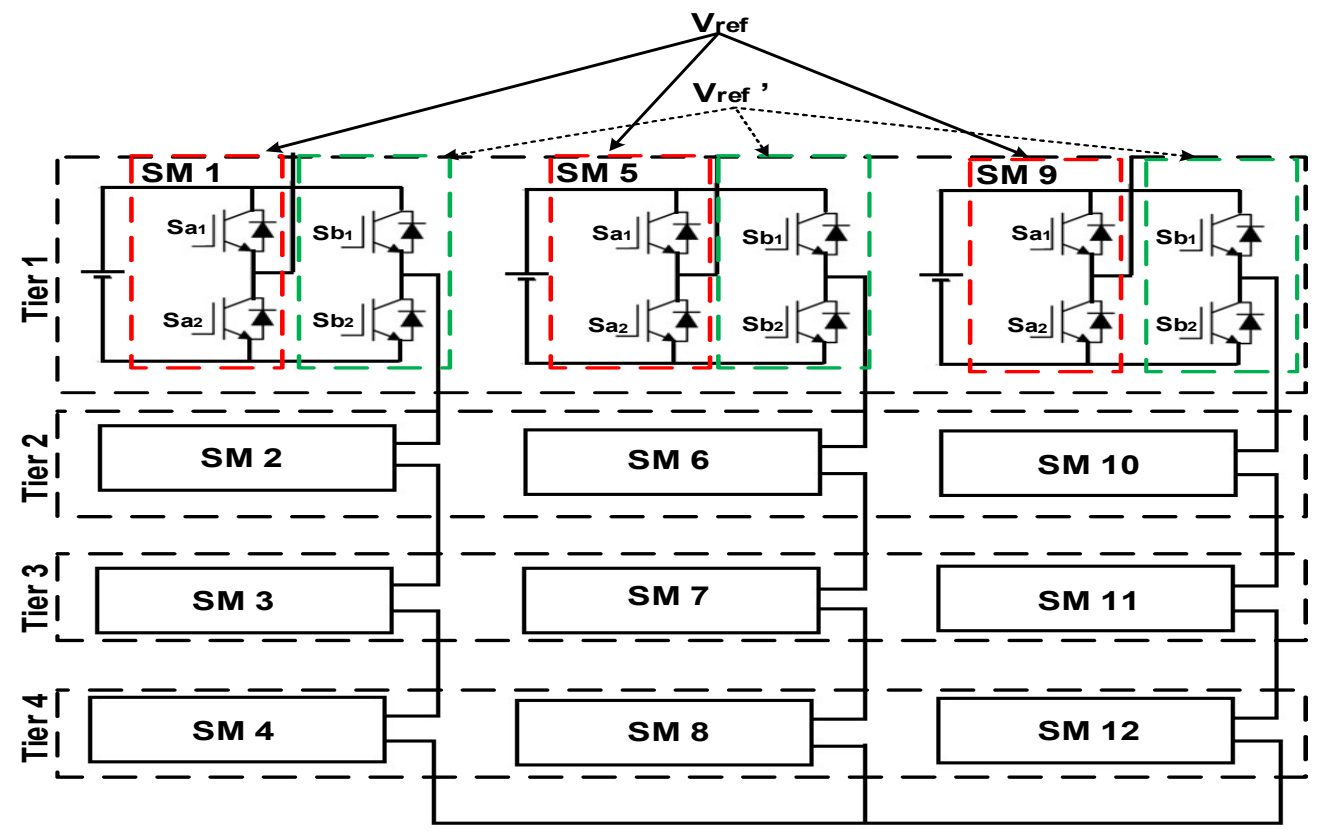

Fig.4. Schematic diagram of a MMCC with four cascaded 3-L H-bridges. 


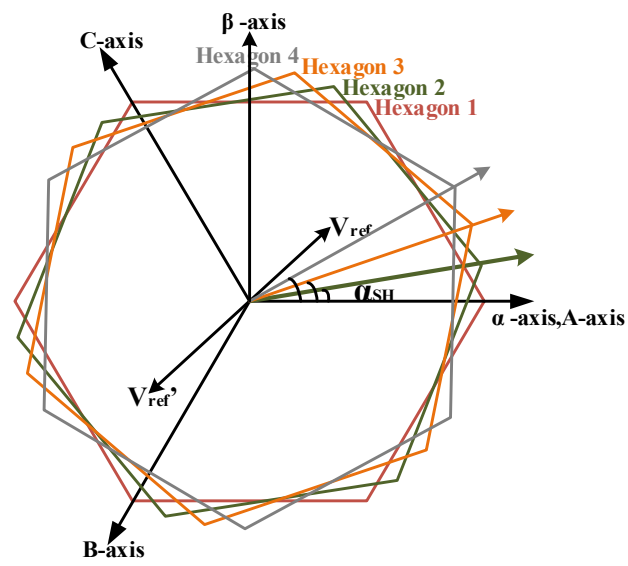

Fig.5. Two-level hexagon for OH-SVM highlighting phase shift between each hexagons.

\section{B. OH-SVM using Three-level Hexagons}

For FC-MMCC modulation, three-level hexagon can also be used. In this case, one tier comprises six FC halfbridges, hence forming two three-phase FC converters, as shown in Fig.2. For a three-level hexagon there are 27 switching state vectors as shown in Fig.7 (a), and sector one is given in Fig.7 (b). Naturally, for MMCC in Fig.2 with only two tiers, two such hexagons, both projected on one pair of $\alpha-\beta$ axes are needed, as shown in Fig.7(c). The phase shift angle $\alpha_{S H}$ between these overlapping 3-level hexagons are evaluated using the same formula (3). Hence if the ratio of the sampling time to the fundamental period is $1 / 5$, according to (3) $\alpha_{S H}=\left(360^{\circ} / 4\right) / 5=18^{\circ}$, resulting in a 2-D representation that contains two interleaved 3-level hexagons, which is twice the angle for the 2-level hexagon case. Similarly due to the phase shift between hexagons, the angular positions of both $\vec{V}_{\text {ref }}$ and $\vec{V}_{\text {ref }}$ '.in each hexagon are also different and are evaluated using equation (4).

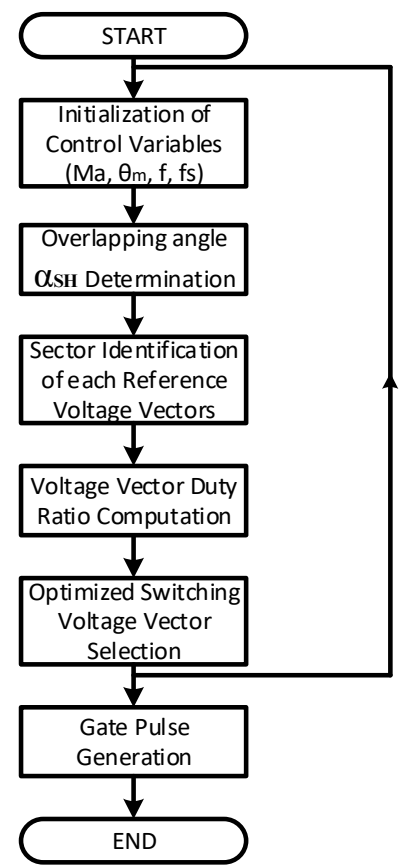

Fig.6. Flowchart for 2-level hexagon implementation 


\section{Sector identification}

Compared to the case when using two-level hexagons, this is slightly more complicated. Firstly, it still requires determining exact locations of the reference voltage vectors, hence the switching states to be applied to switches in each tier. However, this involves identifying the sector number and also locating its vertex in one of the four triangles within the sectors at every time instant. Identification of sector where each reference voltage vector lies can be determined using (5).

Region selection

To find which triangular in the chosen sector the reference voltage vectors are in, considering $\vec{V}_{\text {ref }}$, this is resolved by evaluating voltage vector's corresponding orthogonal components, $V_{S \alpha}, V_{S \beta}$, as:

$$
\begin{aligned}
& V_{S \alpha}=\frac{V_{r e f}}{2 V_{D C}}\left[\cos \theta_{m}-\frac{\sin \theta_{m}}{\sqrt{3}}\right] . \\
& V_{S \beta}=\frac{V_{r e f}}{V_{D C}} \frac{\sin \theta_{m}}{\sqrt{3}} .
\end{aligned}
$$

which are shown in Fig. 7 (b). The values estimated above are then used to identify the relevant triangle according to rules given in Table III. For $m_{a}>0.5$ the regions are seen to be selected between 1,2 and 3 see in Fig. 8.

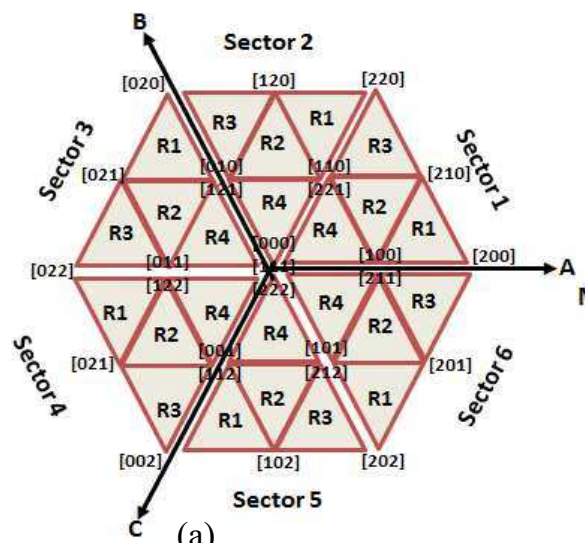

(a)

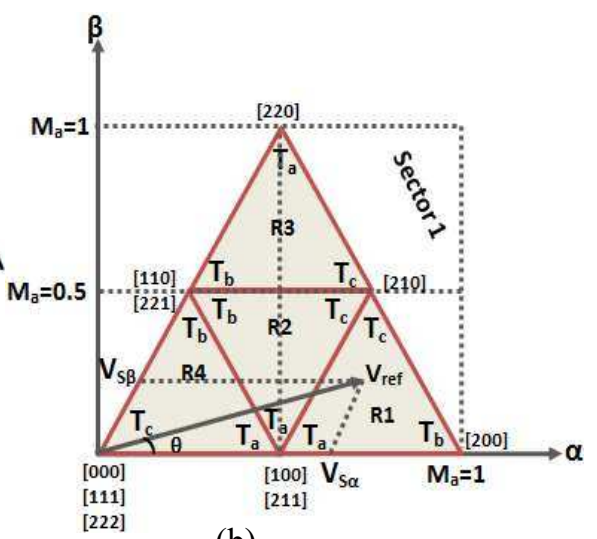

(b)

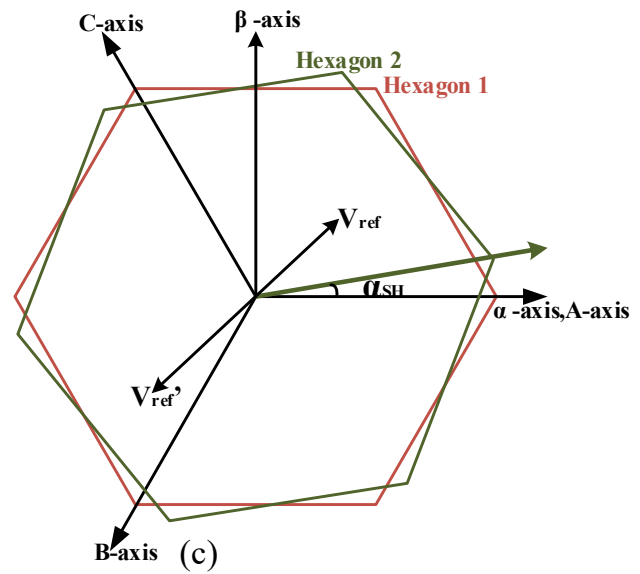

Fig.7. 3-level hexagon for OH-SVM (a) all sectors and reference voltages (b) triangle region detection in sector 1 (c) phase shift between two hexagons. 
Table III: Region selection Criteria $\left(M_{a}=V_{r e f} / V_{D C}\right)$

\begin{tabular}{c|c|c|c}
\hline Region1 & Region 2 & Region3 & Region 4 \\
\hline \multirow{2}{*}{$\mathrm{V}_{\mathrm{S} \alpha}>0.5 \mathrm{M}_{\mathrm{a}}$} & $\mathrm{V}_{\mathrm{S} \alpha}<0.5 \mathrm{M}_{\mathrm{a}}$ & & $\mathrm{V}_{\mathrm{S} \alpha}<0.5 \mathrm{M}_{\mathrm{a}}$ \\
& $\mathrm{V}_{\mathrm{S} \beta}<0.5 \mathrm{M}_{\mathrm{a}}$ & $\mathrm{V}_{\mathrm{S} \beta}>0.5 \mathrm{M}_{\mathrm{a}}$ & $\mathrm{V}_{\mathrm{S} \beta}<0.5 \mathrm{M}_{\mathrm{a}}$ \\
& $\mid \mathrm{V}_{\mathrm{S} \alpha}+\mathrm{V}_{\mathrm{S} \beta}>0.5 \mathrm{M}_{\mathrm{a}}$ & & $\left|\mathrm{V}_{\mathrm{S} \alpha}+\mathrm{V}_{\mathrm{S} \beta}\right|<0.5 \mathrm{M}_{\mathrm{a}}$ \\
\hline
\end{tabular}

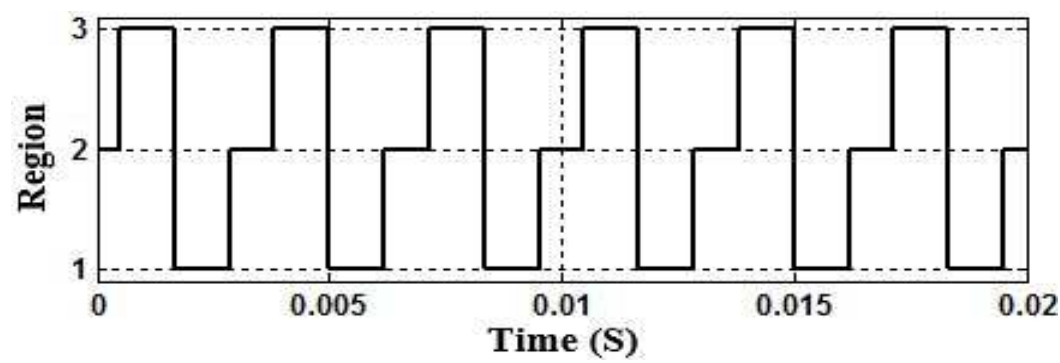

Fig.8. Region selection for $m_{a}>0.5$.

Once the correct triangle region is identified, the switching states can be determined as the three vectors located closest to the vertices of the chosen region. However for an MMCC with 5L-FC converter sub-modules, each location corresponds to four switching states; two of these are independent but the other two give the same voltage level with different switching states, due to the inner floating capacitors in the module. For example, the switching vectors for sector 1, triangle 1 are 200, 210, 100 and 211 shown in Fig.7 (b). The latter two create redundancy and the one to be chosen should be able to re-balance the floating capacitor voltage. The corresponding three duty cycles, $T_{a}, T_{b}$ and $T_{c}$ are calculated using formulae in Table IV at every sample instant of duration $T_{S}$ and should satisfy the condition:

$$
T_{s}=T_{a}+T_{b}+T_{c}
$$

Optimal switching state/voltage vector sequence

The sequence of switching states applied for MMCCs of 5L-FC module follows criteria of obtaining natural balancing of the floating capacitor voltages, and having the least number of switches changing states per sample (i.e. switch transition), hence reducing switching losses. Selection of the optima switching sequence for satisfying the above criteria can be seen from an example as following. Consider the case when $\vec{V}_{\text {ref }}$ is in sector 1 , region 1 , $\mathrm{R}_{1}$, three switching sequences can be applied within a sample period; these are.

$$
\begin{array}{lr}
100 \rightarrow 200 \rightarrow 210 \rightarrow 211 \rightarrow 211 \rightarrow 210 \rightarrow 200 \rightarrow 100 & \text { sequence 1 } \\
210 \rightarrow 200 \rightarrow 100 \rightarrow 210 \rightarrow 210 \rightarrow 100 \rightarrow 200 \rightarrow 210 & \text { sequence 2 } \\
200 \rightarrow 210 \rightarrow 211 \rightarrow 200 \rightarrow 200 \rightarrow 211 \rightarrow 210 \rightarrow 200 & \text { sequence 3 }
\end{array}
$$


Each of the 8 switching vectors in one of the above sequences expresses the switching states for three 5L-FC phase limbs (either LHS or LHS). Since there are two complementary switch pairs in a phase limb of 5L-FC (i.e. $\mathrm{Sa}_{1}-\mathrm{Sa}_{3}$ and $\mathrm{Sa}_{2}-\mathrm{Sa}_{4}$, as seen in Fig. 9), 100 means phase $\mathrm{A}$ limb $\mathrm{Sa}_{1}$ on and $\mathrm{Sa}_{2}$ off, both phases $\mathrm{B}$ and $\mathrm{C} \mathrm{Sa}_{1}$ on and $\mathrm{Sa}_{2}$ are all off, 200 means phase $\mathrm{A}$ limb both $\mathrm{Sa}_{1}$ and $\mathrm{Sa}_{2}$ on, In analyzing these sequence patterns, the direction of current flowing in the sub-module is taken to be positive, out to be negative, thus the capacitor $\mathrm{Ca}_{1}$ is in charging mode when $\mathrm{Sa}_{1}$ and $\mathrm{Sa}_{2}$ state combination is 1:0, in discharging is $0: 1$ and bypassing is 1:1 or 0:0.

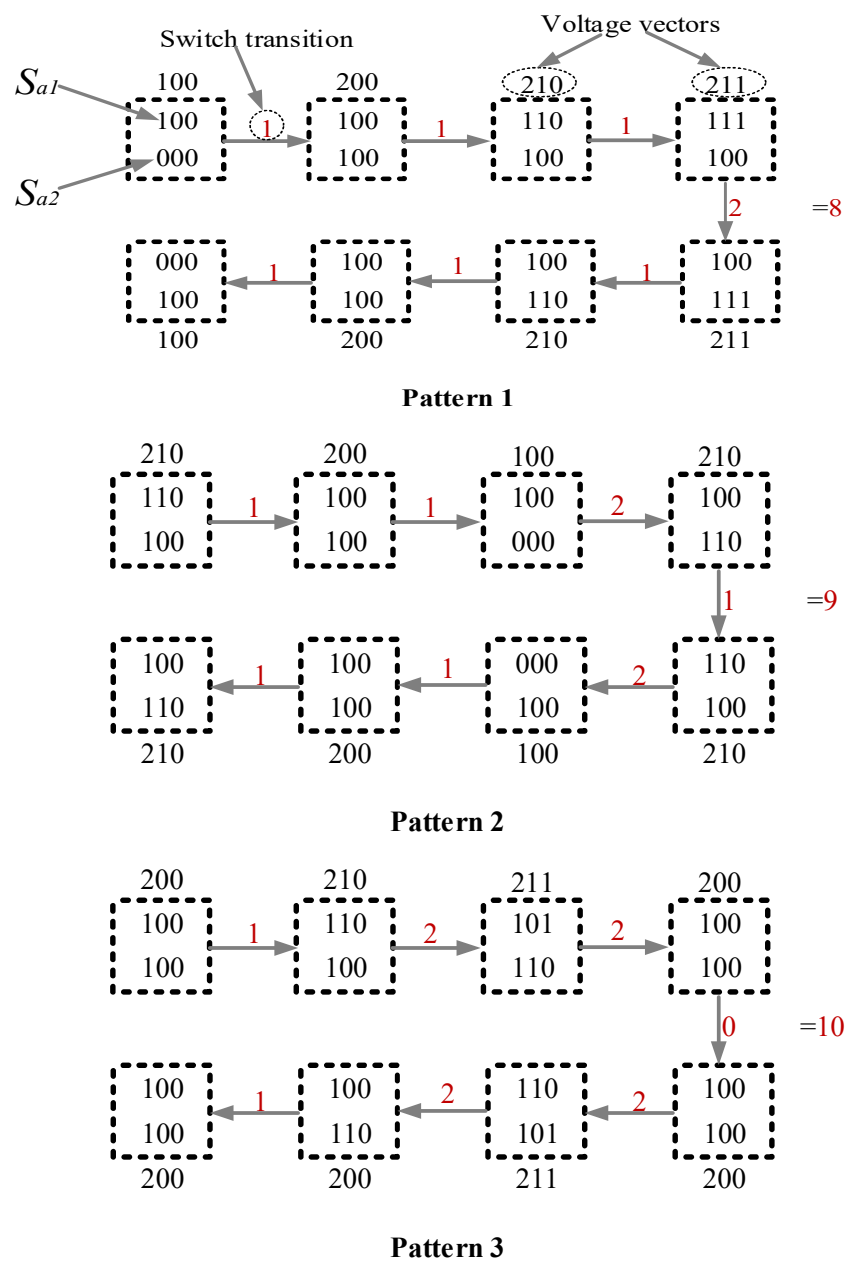

Fig.9. Sector 1 region 1 sequence patterns

All three sequences satisfy the first requirement since they all ensure equal charge/discharge durations of $\mathrm{Ca}_{1}$. However in terms of switch transition action, sequence 1 shows the least number of transition compared to the other sequences and thus being applied. This method is used in every sample interval in the implementation.

Table $\mathrm{V}$ shows the switching state vector sequence table for implementing the 3-level hexagon $\mathrm{SVM}$ where $\mathrm{U}=\mathrm{V}_{\text {ref }}$ and $\mathrm{V}=\mathrm{V}_{\text {ref }}$ ' denote the vectors used for the LHS and RHS limbs of the full bridge FC converter in a tier over one switching period $T_{s}$. Here $\vec{V}_{\text {ref }}$ is located in sector 1, region 1 and $\vec{V}_{\text {ref }}$ ' is located in sector 4, region 1 of the 3-level 
hexagon. By convention in SVM, $T_{s}$ and calculated switching vector times, $T_{a}, T_{b}$, and $T_{c}$ are split in half and arranged as shown in Table V. It can be observed that all floating capacitors of LHS and RHS FC modules are being charged and discharged and vice versa, for an equal number of times within a $T_{s}$ cycle. With this approach implemented for all the 24 triangle regions of the 3-level hexagons, optimal natural voltage balancing of the 5LFC modules can be achieved.

Fig.10 shows the flowchart for implementing the 3-level hexagon technique which is similar to that when using the 2-level hexagons as shown in Fig. 6. Except it has an additional part for the region selection.

\section{Simulation StUdies}

To validate the overlapping hexagon SVM methods both the 2-level and 3-level hexagon schemes are applied to control an MMCC having two 5L-FC bridges per phase limb via simulation. The results are compared with that using the conventional multilevel SVM method in terms of waveform quality, switching losses, natural balancing capability of the inner flying capacitor and computational complexity. In addition, the 2-level hexagon SVM is applied to control an MMCC having four 3L-FB per phase and the results are compared with MMCC of two cascaded 5L-FCs per phase.. The parameters of sub-modules 5L-FC and 3L-FB are listed in Appendix (1).

Table IV: Duty Cycle calculation formulae

\begin{tabular}{|c|c|}
\hline Region 1 & Region 2 \\
\hline$T_{a}=2 T_{s}\left(1-\frac{V_{r e f}}{\sqrt{3} V_{D C}} \sin \left(\frac{\pi}{3}+\theta_{m}\right)\right)$ & $T_{a}=T_{s}\left(1-\frac{2 V_{r e f}}{\sqrt{3} V_{D C}} \sin \theta_{m}\right)$ \\
\hline$T_{b}=T_{s}\left(\frac{2 V_{r e f}}{\sqrt{3} V_{D C}} \sin \left(\frac{\pi}{3}+\theta_{m}\right)-1\right)$ & $T_{b}=2 T_{s}\left(1-\frac{V_{r e f}}{\sqrt{3} V_{D C}} \sin \left(\frac{\pi}{3}+\theta_{m}\right)\right)$ \\
\hline$T_{c}=T_{s}\left(\frac{2 V_{r e f}}{\sqrt{3} V_{D C}} \sin \theta_{m}\right)$ & $T_{c}=T_{s}\left(\frac{2 V_{r e f}}{\sqrt{3} V_{D C}} \sin \left(\frac{\pi}{3}-\theta_{m}\right)-1\right)$ \\
\hline$T_{a}=T_{s}\left(\frac{2 V_{r e f}}{\sqrt{3} V_{D C}} \sin \theta_{m}-1\right)$ & $T_{a}=T_{s}\left(\frac{2 V_{r e f}}{\sqrt{3} V_{D C}} \sin \left(\frac{\pi}{3}-\theta_{m}\right)\right)$ \\
\hline$T_{b}=2 T_{s}\left(1-\frac{V_{r e f}}{\sqrt{3} V_{D C}} \sin \left(\frac{\pi}{3}+\theta_{m}\right)\right)$ & $T_{b}=T_{s}\left(\frac{2 V_{r e f}}{\sqrt{3} V_{D C}} \sin \theta_{m}\right)$ \\
\hline$T_{c}=T_{s}\left(\frac{2 V_{r e f}}{\sqrt{3} V_{D C}} \sin \left(\frac{\pi}{3}-\theta_{m}\right)\right)$ & $T_{c}=T_{s}\left(1-\frac{2 V_{r e f}}{\sqrt{3} V_{D C}} \sin \left(\frac{\pi}{3}+\theta_{m}\right)\right)$ \\
\hline
\end{tabular}


Table V: Vector combination chart showing optimized sequence of switching states for LHS and RHS switches when $\mathrm{V}_{\text {ref }}$ in region 1 sector 1 and $\mathrm{V}_{\text {ref }}$ ' in region 1 sector 4

Green=charging state and Red= discharging state

\begin{tabular}{|c|c|c|c|c|c|c|c|c|c|c|c|c|c|c|c|c|c|}
\hline \multirow{2}{*}{\multicolumn{2}{|c|}{ phase }} & \multicolumn{2}{|c|}{$\mathrm{T}_{\mathrm{a}} / 4$} & \multicolumn{2}{|c|}{$T_{b} / 2$} & \multicolumn{2}{|c|}{$T_{c} / 2$} & \multicolumn{2}{|c|}{$T_{a} / 4$} & \multicolumn{2}{|c|}{$T_{a} / 4$} & \multicolumn{2}{|c|}{$\mathrm{T}_{c} / 2$} & \multicolumn{2}{|c|}{$T_{b} / 2$} & \multicolumn{2}{|c|}{$\mathrm{T}_{\mathrm{a}} / 4$} \\
\hline & & $\mathbf{L}$ & $\mathbf{R}$ & $\mathbf{L}$ & $\mathbf{R}$ & $\mathbf{L}$ & $\mathbf{R}$ & $\mathbf{L}$ & $\mathbf{R}$ & L & $\mathbf{R}$ & & $\mathbf{R}$ & & $\mathbf{R}$ & & $\mathbf{R}$ \\
\hline \multirow{6}{*}{$\begin{array}{c}\text { Region } \\
1\end{array}$} & A & 1 & 0 & 1 & 0 & 1 & 0 & 1 & 1 & 1 & 0 & 1 & 0 & 1 & 0 & 0 & 0 \\
\hline & & 0 & 0 & 1 & 0 & 1 & 0 & 1 & 0 & 1 & 1 & 1 & 0 & 1 & 0 & 1 & 0 \\
\hline & $B$ & 0 & 1 & 0 & 1 & 1 & 1 & 1 & 1 & 0 & 1 & 0 & 1 & 0 & 1 & 0 & 0 \\
\hline & & 0 & 0 & 0 & 1 & 0 & 1 & 0 & 1 & 1 & 1 & 1 & 1 & 0 & 1 & 0 & 1 \\
\hline & C & 0 & 1 & 0 & 1 & 0 & 1 & 1 & 1 & 0 & 1 & 0 & 0 & 0 & 1 & 0 & 0 \\
\hline & & 0 & 0 & 0 & 1 & 0 & 0 & 0 & 1 & 1 & 1 & 0 & 1 & 0 & 1 & 0 & 1 \\
\hline & & \multicolumn{8}{|c|}{$\mathrm{T}_{\mathrm{S}} / 2$} & \multicolumn{8}{|c|}{$\mathrm{T}_{\mathrm{S}} / 2$} \\
\hline
\end{tabular}

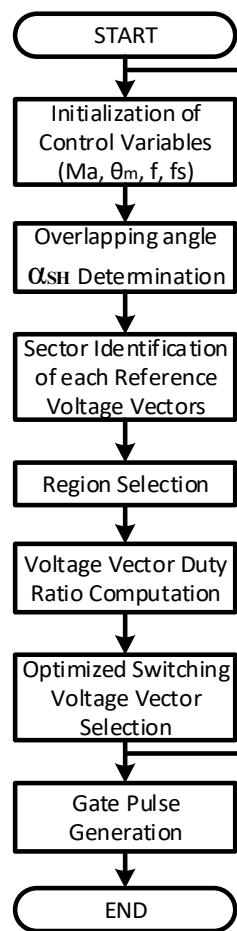

Fig.10. Flowchart for 3-level hexagon implementation.

\section{A. Application of OH-SVM schemes to MMCC of $5 \mathrm{~L}-\mathrm{FC}$ Modules}

Fig.11(a)-(f) show the voltage and current waveforms produced respectively using conventional multilevel SVM and those shown in Fig.12(a)-(f) and Fig.13(a)-(f) are respectively from OH-SVM schemes using 2-level hexagon and 3-level hexagon. As can be seen, all these schemes lead to the converter generating 9-level (peak to peak) output phase voltages with good harmonic performance. However, the voltage and current waveforms generated from using the 2-level and 3-level OH-SVM show better performance than that from the conventional multilevel SVM method, as shown by its phase and line-line voltage waveforms in Fig. 11. This is also clear from voltage spectra and THD values which are all lower than the ones given by the conventional method as listed in Table VI. 
For the phase limb output voltage, the harmonics appear as sidebands centered around 8 , and 4 times of the actual switching frequency for 2-level, 3-level hexagon methods but only 2 times with using conventional SVM, i.e. for 2-level hexagon: $f_{h}=\left(j 8 m_{f} \pm k\right) f_{o}$, 3-level hexagon: $f_{h}=\left(j 4 m_{f} \pm k\right) f_{o}$ and for conventional SVM: $f_{h}=\left(j 2 m_{f} \pm k\right) f_{o}$ , where $f_{0}$ is the fundamental frequency, $j=1,2,3 \ldots$ and sideband index $k=1,3,5 \ldots$ odd integers. For line voltage, sideband index, $k=1,5,7$..odd integers, excluding odd multiples of 3 .

The THD values for the phase and line-line voltage waveforms are $28.22 \%, 12.7 \%$ for 3 -level hexagon and $22.89 \%, 8.47 \%$ for 2 -level hexagon. The differences in these values are due to the fact that for the 3-level hexagon more harmonic elements appear as the sideband around the $4^{\text {th }}$ multiple of the switching frequency, whilst for the 2-level hexagon these harmonics are significantly lower and only appear as sidebands centered around $8 m_{f}$.

From the above spectra analysis it can be seen that using the same switching frequency $f_{s}$ for the sub-modules at each tier, the effective switching frequencies $\sum f_{s}$, seen across the resultant phase voltage waveforms for each methods are increased. This difference is due to the time staggering or overlapping effect between voltage tiers. For conventional SVM method $\sum f_{\mathrm{s}}=2 f_{s}$ due to unipolar switching, while for $3 \mathrm{~L}$ and $2 \mathrm{~L}$ hexagon methods, the effective switching frequencies are respectively $4 f_{s}$ and $8 f_{s}$. In other words, there are more transitions in the output waveform because they are spaced out in time. The switching losses are not increased because the number of switch transitions per cycle, in each tier, is not increased. Thus if using the $2 \mathrm{~L}$ hexagon overlapping method, for obtaining the same effective frequency as that of the classic SVM, the actual switching frequency for sub-modules can be lowered to only $1 / 4$ th of that used for the conventional method. If $3 \mathrm{~L}$ hexagon is used the actual switching frequency can be a half. The reduction of switching frequency certainly reduces the switching losses and is not at the expense of the voltage waveform quality see Fig.14.

With adequate switching vector sequence applied, both the 3-level hexagon and conventional SVM can ensure natural balance of inner floating capacitor voltages. However the capacitor voltage fluctuations when using the 2level hexagon are seen to be the lowest, followed by the 3-level hexagon and then conventional SVM with values being $\pm 0.6 \mathrm{~V}, \pm 1.5 \mathrm{~V}$ and $\pm 10 \mathrm{~V}$ respectively. This is attributed to the overlapping nature of both 2 and 3-level hexagons.

Based on the SIMULINK models, the computational load for each SVM algorithm is compared and listed in Table VII. According to the sum of arithmetic operations, such as addition, subtraction, division, multiplication and trigonometric functions, the classical multilevel SVM requires the highest computational burden amongst three, the 2-level OH-SVM is the most computationally efficient method. 


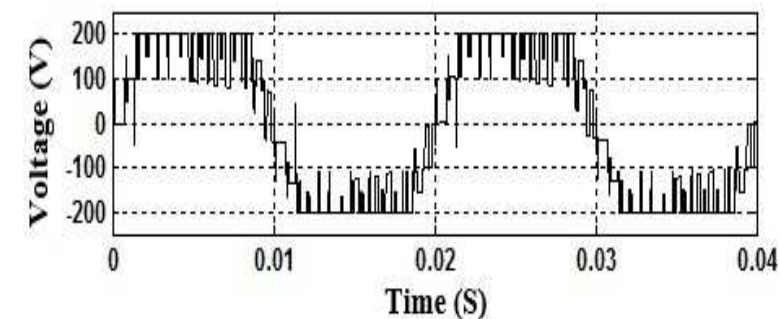

(a)
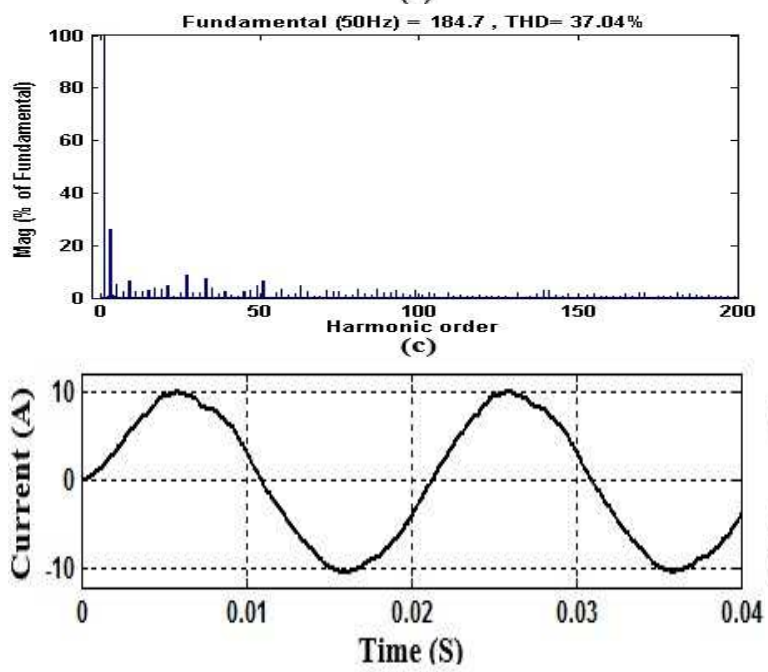

(e)

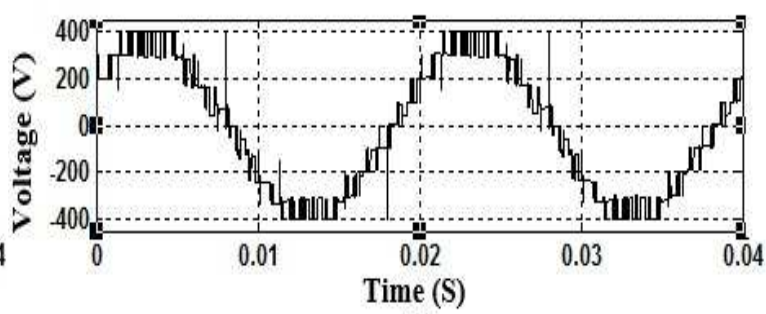

(b)
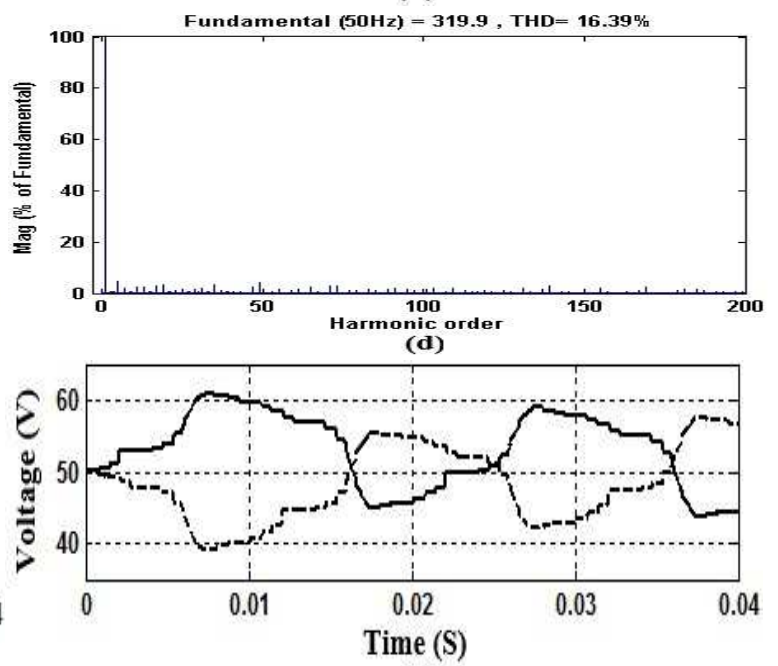

(f)

Fig.11. Classical multilevel SVM simulations (a) phase voltage (b) Line-line voltage (c) Phase voltage frequency spectra \& THD (d) Line-line voltage frequency spectra \& THD (e) load phase current (f) Module floating Capacitor voltage waveforms.

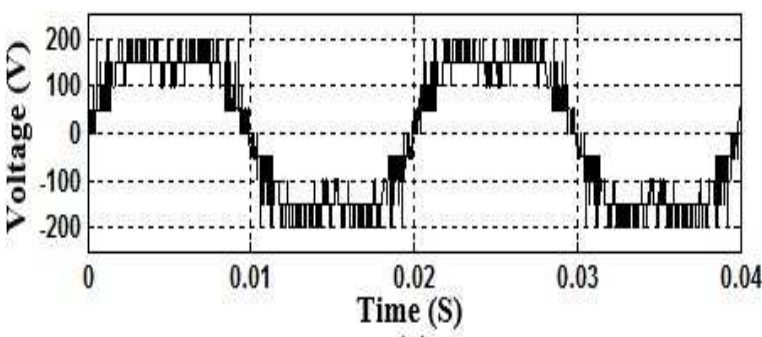

(a)
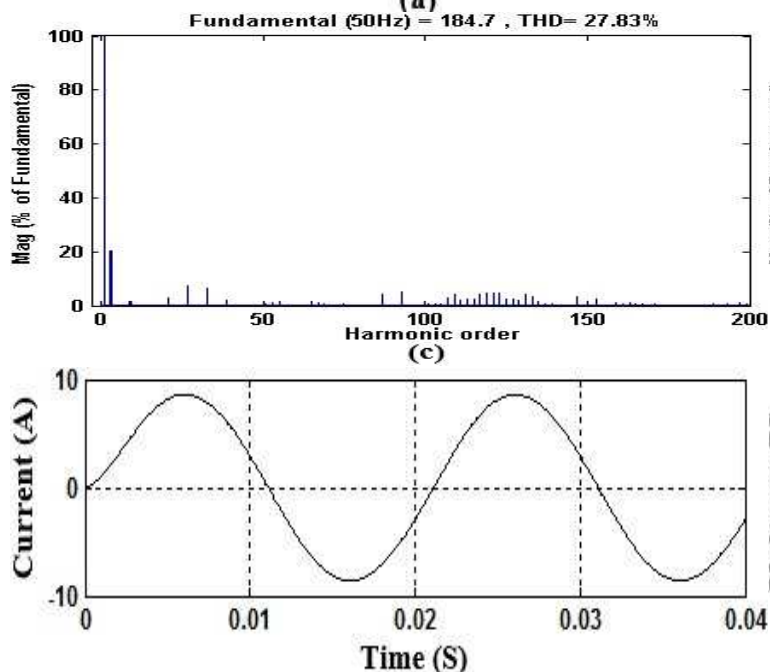

(e)

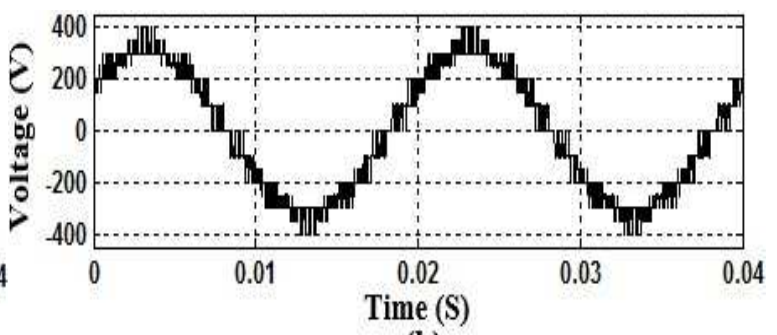

(b)

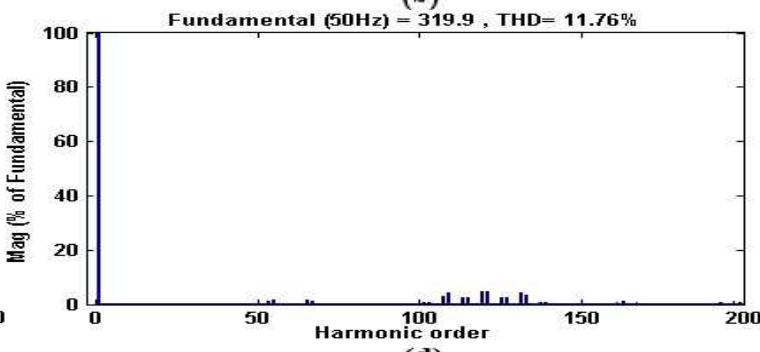

(d)

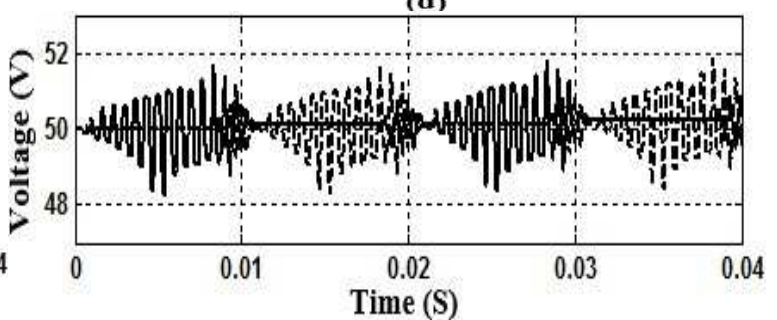

(f)

Fig. 12. 3-level OH-SVM simulations (a) phase voltage (b) Line-line voltage (c) Phase voltage frequency spectra \& THD (d) Line-line voltage frequency spectra \& THD (e) phase current (f) Module floating Capacitor voltage waveforms. 


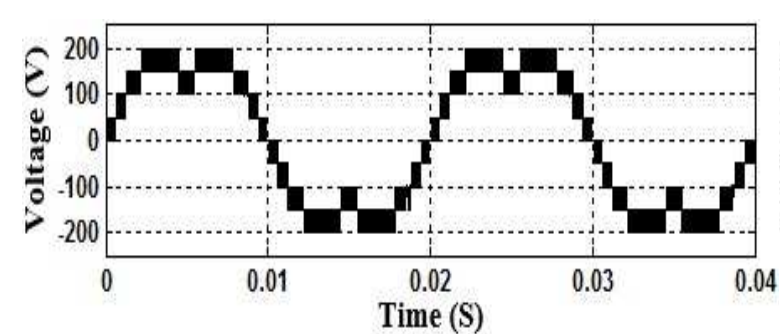

(a)

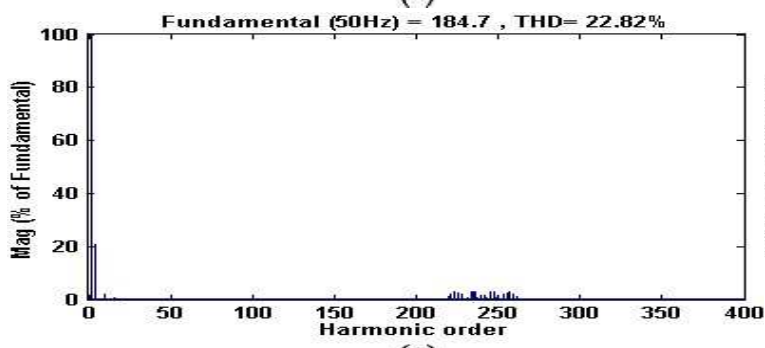

(c)

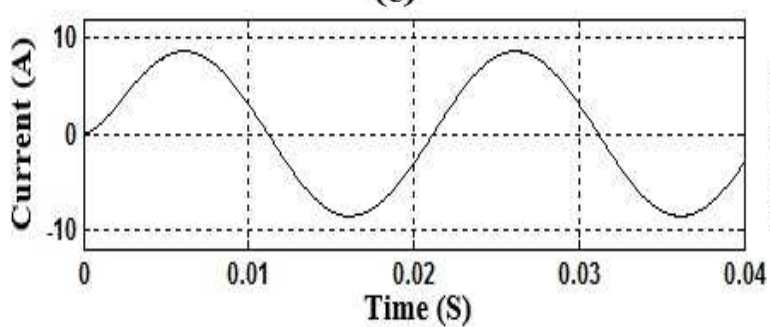

(e)

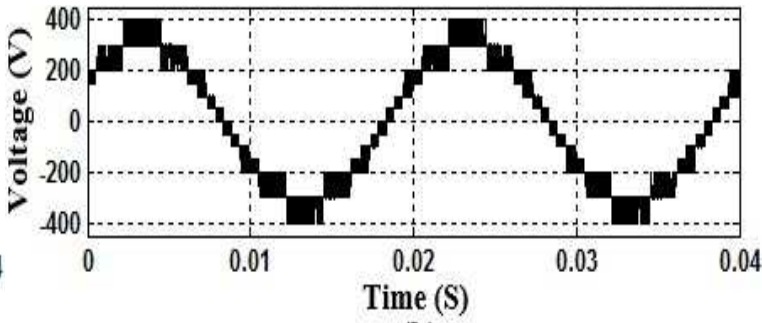

(b)

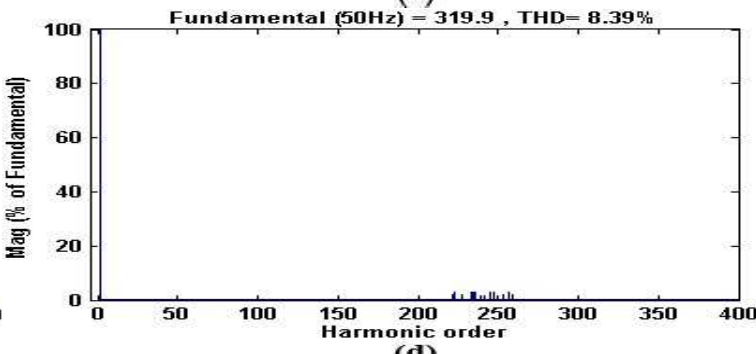

(d)

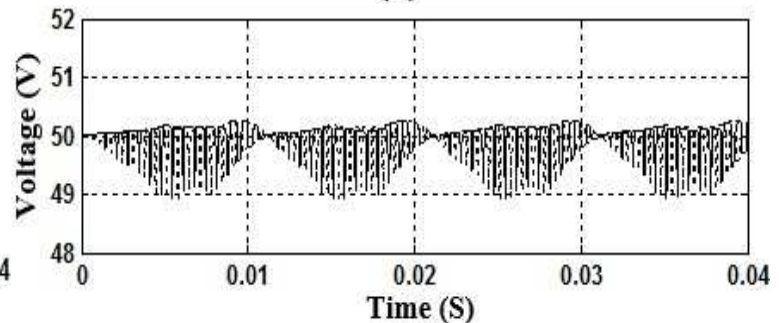

(f)

Fig.13. 2-level OH-SVM simulations (a) phase voltage (b) Line voltage (c) Phase voltage frequency spectra \& THD (d) Line-line voltage frequency spectra \& THD (e) load phase current (f) Module floating Capacitor voltage waveforms.

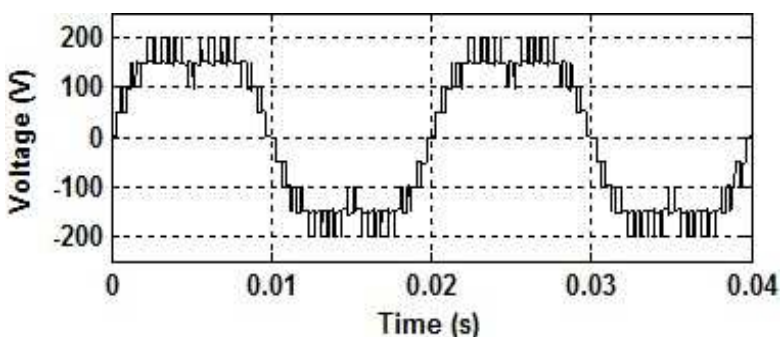

(a)

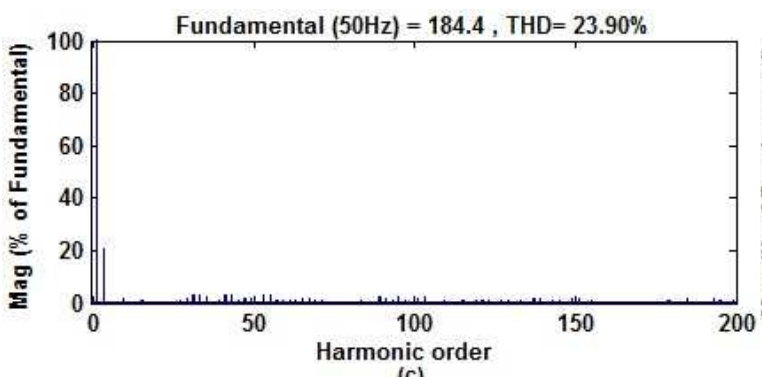

(c)

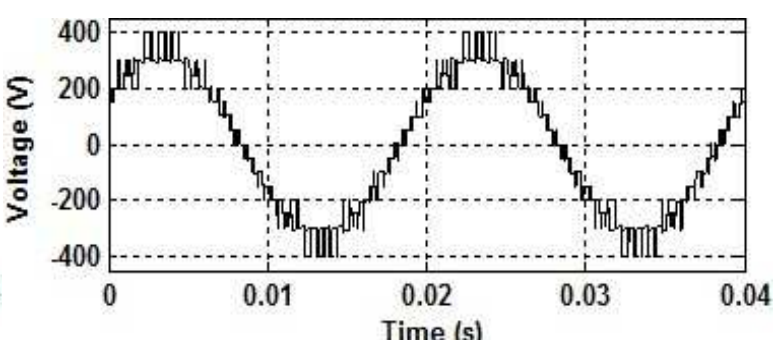

(b)

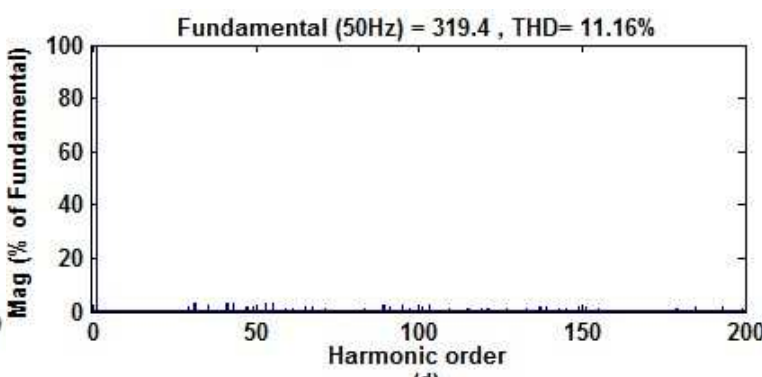

(d)

Fig.14. 2-level OH-SVM simulations (a) phase voltage (b) Line voltage (c) Phase voltage frequency spectra \& THD and (d) Line-line voltage frequency spectra \& THD at $300 \mathrm{~Hz}$ switching frequency. 
Table VI: Comparison of OH-SVM Schemes

\begin{tabular}{c|c|c|c}
\hline Phase shifted-SVM schemes & $\begin{array}{c}\text { 2-level } \\
\text { hexagon }\end{array}$ & $\begin{array}{c}\text { 3-level } \\
\text { hexagon }\end{array}$ & $\begin{array}{c}\text { Conventional } \\
\text { SVM }\end{array}$ \\
\hline Phase voltage THD (\%) & 22.82 & 27.83 & 37.04 \\
\hline Line voltage THD (\%) & 8.39 & 11.76 & 16.39 \\
\hline Phase Current THD (\%) & 2.35 & 2.50 & 3.79 \\
\hline FC voltage Variation (\%) & $\pm 1.2 \%$ & $\pm 3 \%$ & $\pm 20 \%$ \\
\hline
\end{tabular}

Table VII: Comparison of Computational Load for the SVM Schemes

\begin{tabular}{c|c|c|c}
\hline $\begin{array}{c}\text { Computational } \\
\text { Task in each } \\
\text { section }\end{array}$ & $\begin{array}{c}\text { 2-level } \\
\text { hexagon }\end{array}$ & $\begin{array}{c}\text { 3-level } \\
\text { hexagon }\end{array}$ & $\begin{array}{c}\text { Conventional } \\
\text { SVM }\end{array}$ \\
\hline $\mathrm{V}_{\text {ref \& } \mathrm{V}_{\text {ref' angle }}}$ & 8 & 4 & 2 \\
\hline Sector Selection & 8 & 4 & 2 \\
\hline Region Selection & - & 96 & 384 \\
\hline $\begin{array}{c}\text { Duty Ratio } \\
\text { calculation }\end{array}$ & 144 & 288 & 576 \\
\hline Total & 160 & 392 & 964 \\
\hline
\end{tabular}

\section{B. Application of 2-Level OH-SVM to MMCCs of different Module Topologies}

The MMCCs chosen for this study are the ones using, either four 3L-FB, two 5L-FC or 5L-FC-H (shown in Fig. 1

(c)) modules. With the same total DC voltage, and modulation index these should generate the same output voltage levels, while controlled by the 2-level OH-SVM. Figs.15 (a)-(e) show results from the MMCC of four 3L-FB modules per phase and Figs.16 (a)-(g) are those from that having two 5L-FC-H modules per phase. 5L-FC results are already shown in Fig. 13. Clearly the waveforms from 3L-FB and 5L-FC show superior performance, as they have the same phase and line-line voltage THDs (Fig.15 (c), (d) and Fig.13 (c), (d)) which are all lower than that of $5 \mathrm{~L}-\mathrm{FC}-\mathrm{H}$, which are $34.13 \%$ and $21.31 \%$, respectively.

In this hybrid case the LHS two FCs requires four 2-level hexagons with equal phase shift between them but the RHS two full-bridge requires only two that has an overlapping angle of twice the hexagons on the LHS.

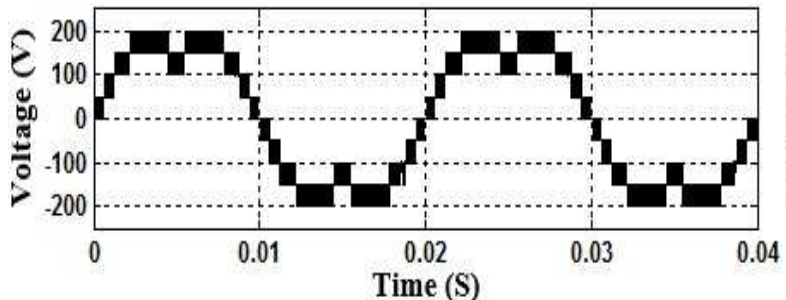

(a)

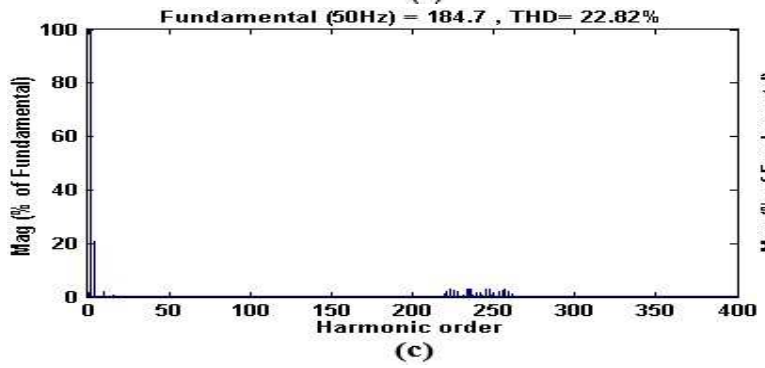

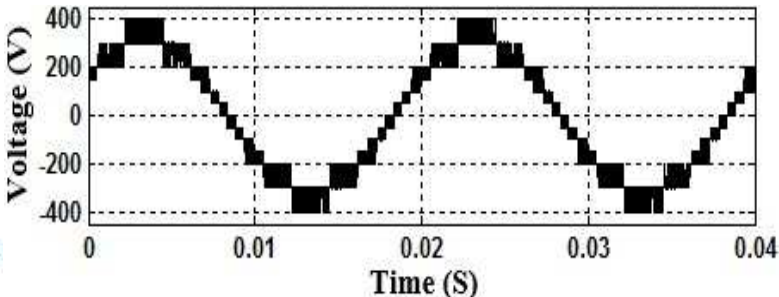

(b)

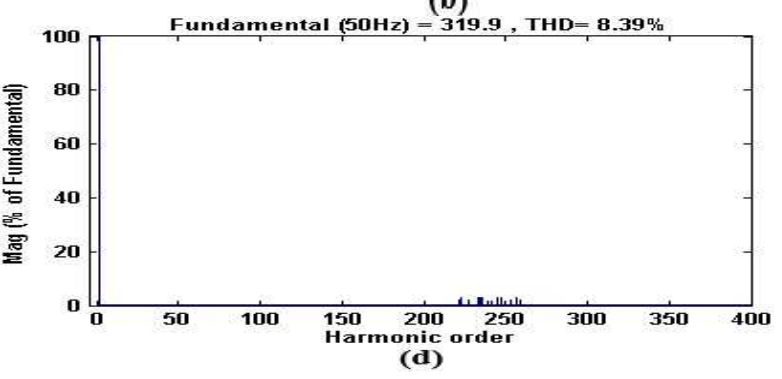




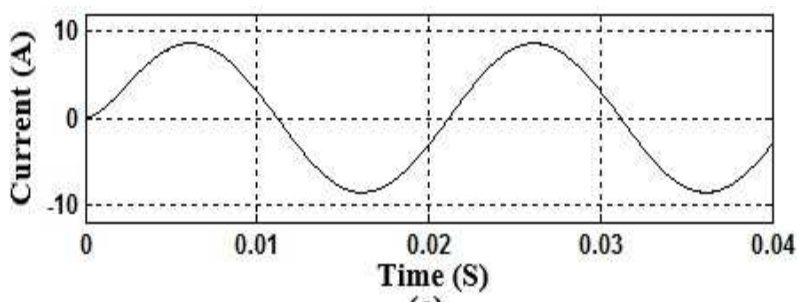

(e)

Fig.15. 2-level OH-SVM control of MMCC of 3L-FB (a) phase voltage (b) Line voltage (c) Phase voltage spectra $\&$ THD (d) Line-line voltage spectra \& THD (e) phase current

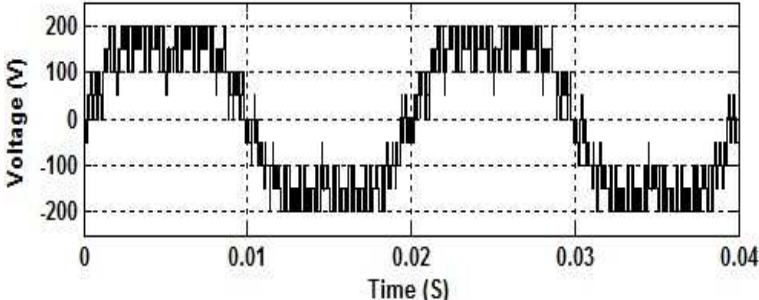

(a)

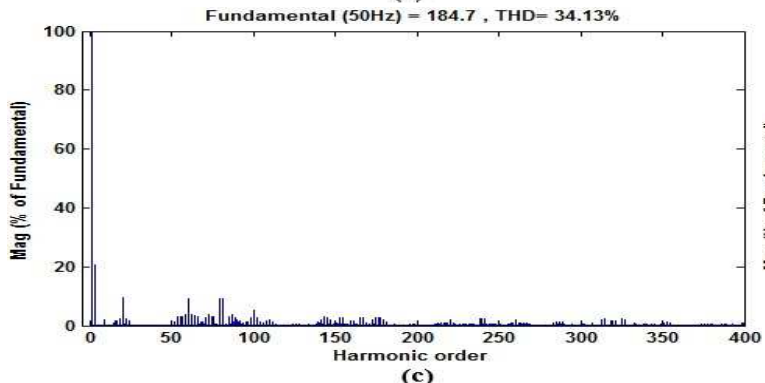

(c)

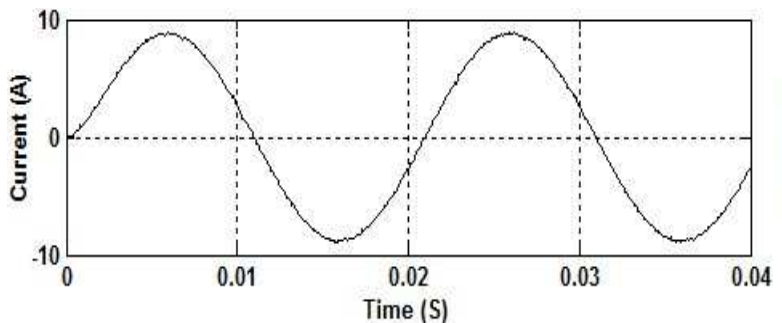

(e)

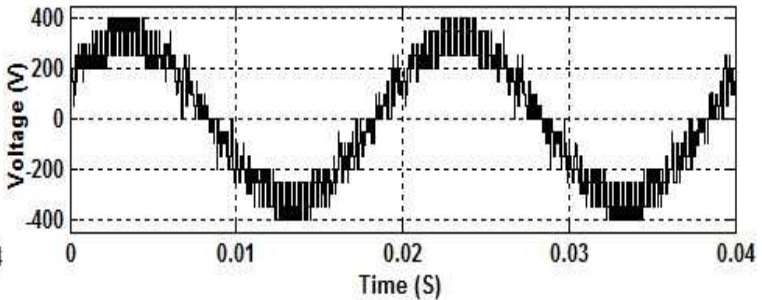

(b)
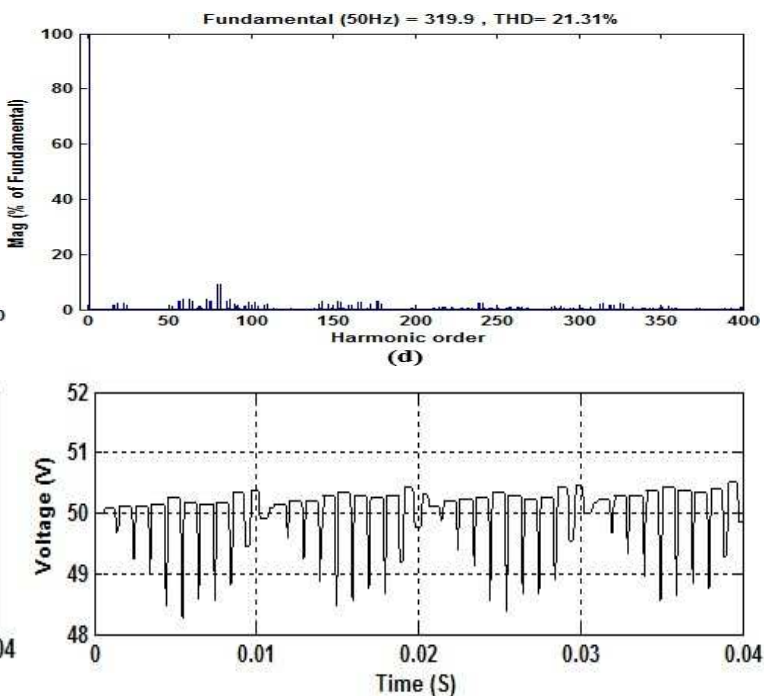

(f)

Fig. 16. 2-level OH-SVM for MMCC of 3L-FC-H (a) Phase voltage (b) Line-line voltage (c) phase voltage spectra \& THD (d) Line voltage spectra \& THD (e) Phase current (f) Modules floating capacitor voltage waveform.

Variations of both phase and line-line voltage THDs against the modulation index $m_{a}$ are investigated for the three different MMCCs. The results are illustrated in Figs.17 (a) and (b). It can be seen that both 3L-FB and 5L-FCbased MMCC give comparably low THD values for $\mathrm{m}_{\mathrm{a}} \geq 0.5$. The MMCC with $5 \mathrm{~L}-\mathrm{FC}-\mathrm{H}$ modules has shown giving the poorest waveform performance amongst the three according to THD values. This is due to that the twolevel half bridge on either LHS or RHS can only offer three voltage levels, 0 volt and $\pm 2 \mathrm{~V}_{\mathrm{DC}}$, so giving less degree of freedom to shape the voltage waveform.

The above simulation studies show clearly the advantage of using OH-SVM of 2-Level hexagon scheme, i.e. it results in very low floating capacitor voltage ripple for FC and FC-H modules, this leads to the use of smaller capacitors hence reducing the costs and footprint of the converters. 


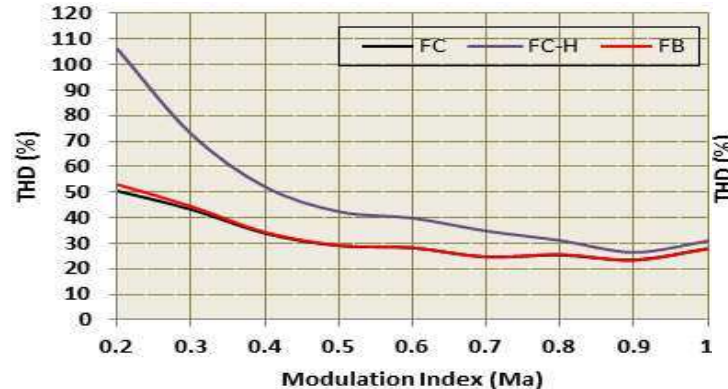

(a)

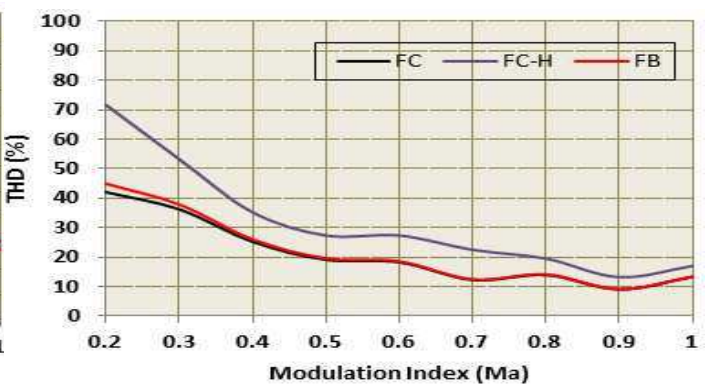

(b)

Fig.17. THD for MMCCs of 5L-FC, 5L-FC-H and 3L-FB modules using 2-Level hexagon OH-SVM (a) phase voltages (b) line to line voltages generated.

The effectiveness of the proposed method when the number of sub-modules per phase is increases is analyzed for $n_{m p}=83 \mathrm{~L}-\mathrm{FB}$ sub-modules. The voltage waveforms and their corresponding spectra quality plots highlights the waveform quality with switching frequency $f_{\mathrm{s}}=300 \mathrm{~Hz}$ (see Fig. 18).

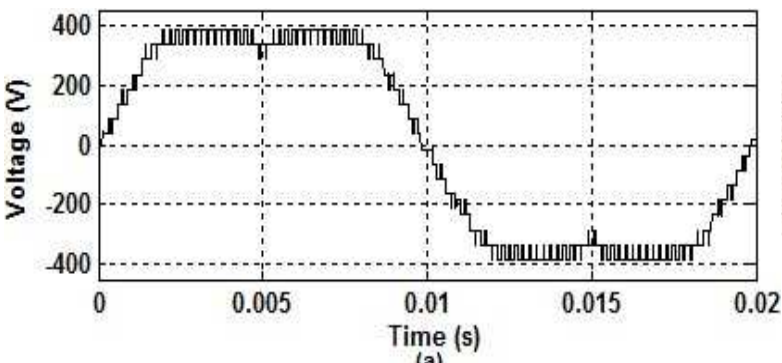

(a)
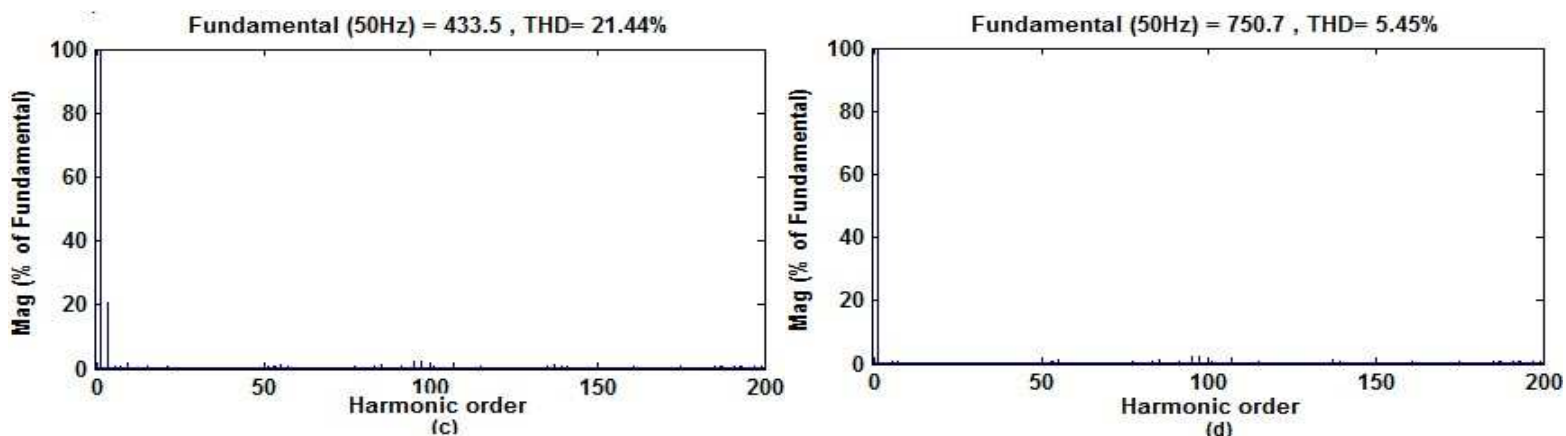

Fig.18. 2-level OH-SVM control of 17-level MMCC using 3L-FB as sub-module (a) Phase voltage (b) Line-line voltage waveforms (c) phase voltage spectra \& THD (d) Line voltage spectra \& THD.

\section{EXPERIMENTAL TEST AND RESUlTS}

An experimental MMCC using two cascaded 3L-FB sub-modules per phase has been built to verify the 2-level hexagon OH-SVM scheme. The switching devices used are IRF740IGBT, each rated at 400V, 10A and the corresponding bypass diodes rated $450 \mathrm{~V}, 10 \mathrm{~A}$. Each of 6 modules is powered by a $20 \mathrm{~V}$ dc power source. The algorithm is implemented using a DSP device, eZdspF28335 from Spectrum Digital [47]. The pulse signals from DSP are applied to drive the cascaded 3L-FB switches. Experimental setup of this simple MMCC is shown in Fig. 19 and the system parameters are listed in Appendix (2). 


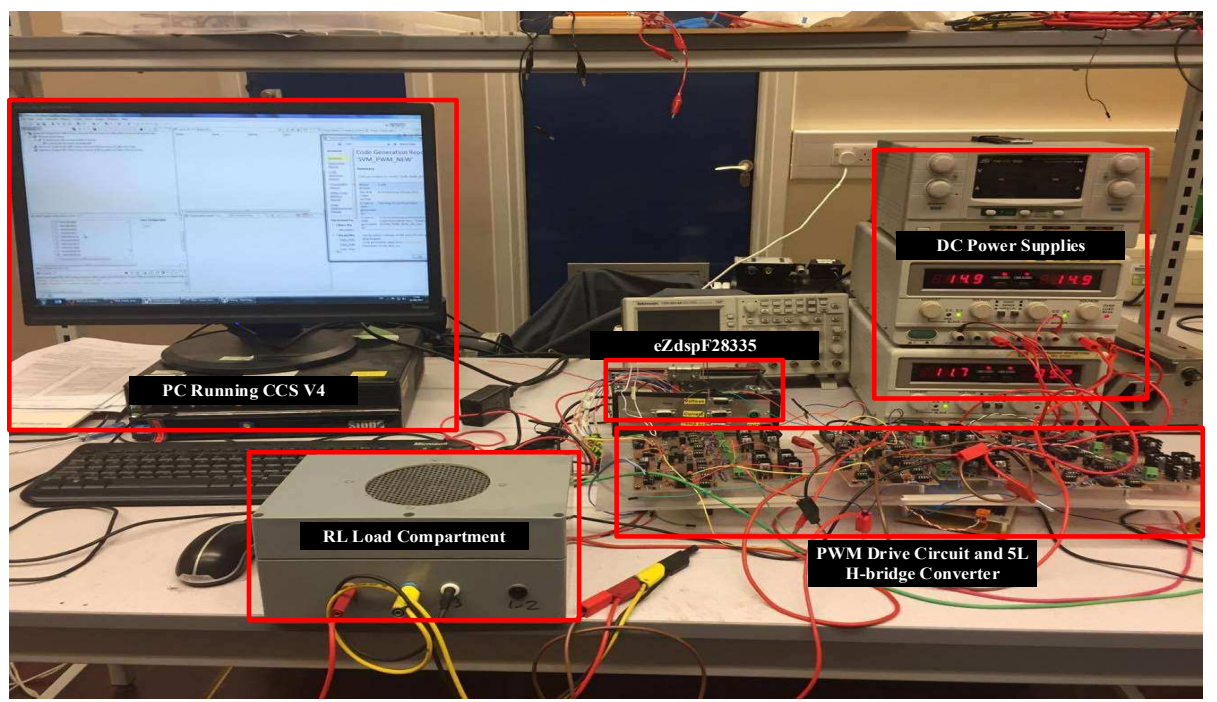

Fig. 19. MMCC Experimental Setup

The sampling/switching frequency is $250 \mathrm{~Hz}$ and modulation index is 0.8 . Connected across the three phase of MMCC is a balanced R-L load of $7.5 \Omega$ and $10 \mathrm{mH}$ per phase. Fig. 20 (a)-(d) show, respectively, the plots of the output phase and line-to-line voltage waveforms and spectra which conform to the simulation results in Fig 15.
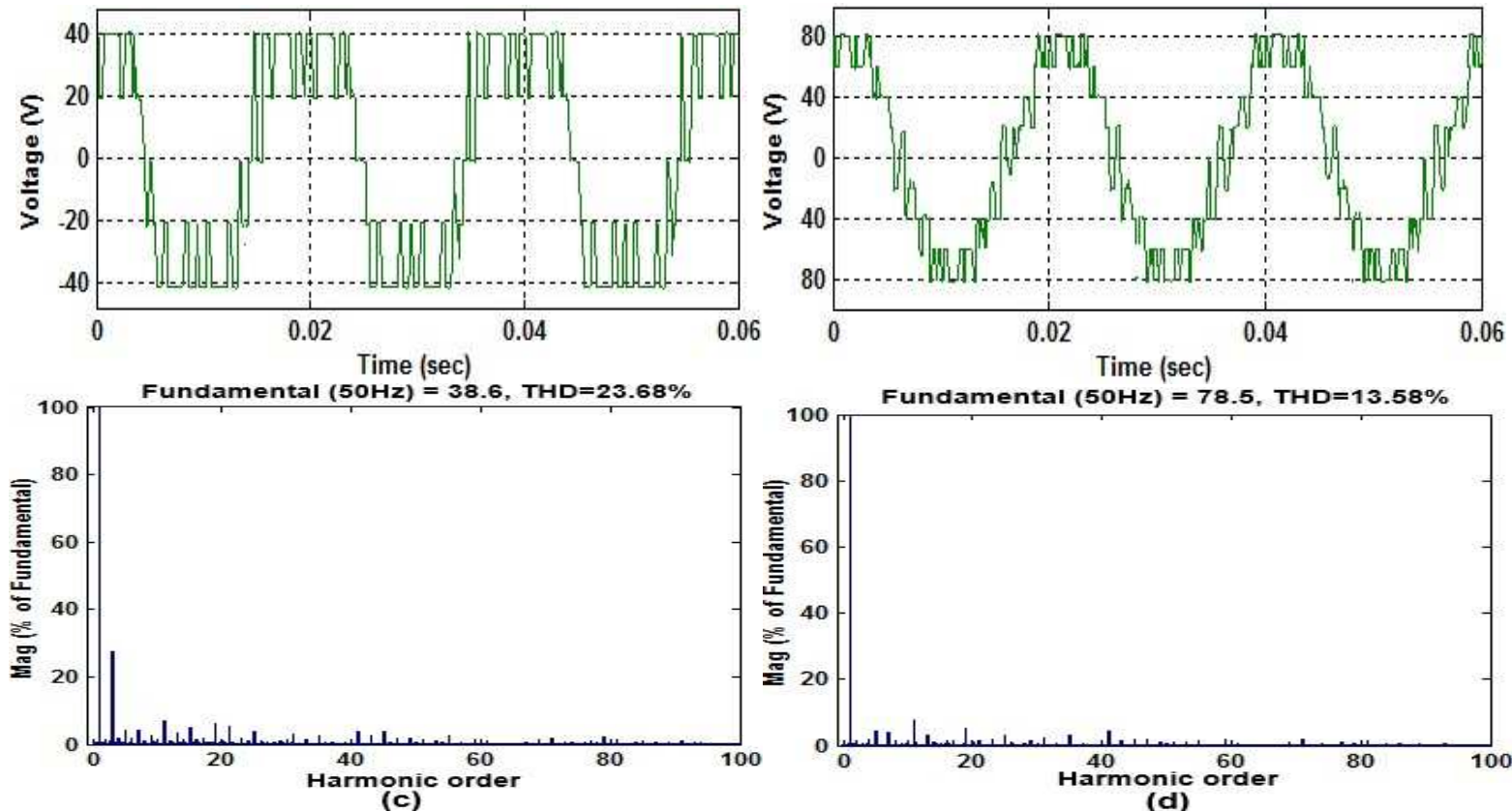

Fig.20. OH-SVM Experimental results: (a) Phase output voltage (b) Line output voltage, (c) Phase voltage spectrum and (d) Line voltage spectrum.

\section{CONCLUSIONS}

The paper presented a novel space vector modulation scheme for three-phase modular multilevel cascaded converters. The method is based on using multiple of overlapped 2-level or 3-level hexagons each copes with one tier of the converter. The approach has the following advantages; the overlapping effect gives equal switch pattern and utilization for modules at different voltage levels in one phase-leg, hence it brings 3L-FB capacitor voltage balance. The method simplifies the switching vector selection and duty cycle calculation procedure compared to 
the conventional multilevel SVM and is flexible in shaping the output voltage waveforms for different applications. The method requires lower switching frequency hence incurring lower switching losses for obtaining voltage waveforms of the harmonic performance. Simulation results show that the best waveform performance is obtained by using the 2-level hexagon scheme, since it gives the lowest phase and line-to-line voltage THD values. With adequate switching sequence selection, this scheme also show being able to balance the iner flying capacitor voltages of the 5L-FC. Simulation results show it gives the least capacitor voltage ripples compared with that when using the 3-level hexagon or conventional multilevel SVM. Experimental verification has been performed on a 6-module H-bridge MMCC using 2-level hexagon scheme. The practical results presented validate the method and show good waveform performance comparable to the simulation output.

\section{Appendix}

(1). Parameters of the simulated MMCC system:

Modulation index (Ma): 0.85;

Switching frequency (fs): $1.5 \mathrm{kHz}$;

Rated DC voltage rating of each FC and FC-H module: 100V;

Rated DC voltage rating of each FB module: $50 \mathrm{~V}$;

Rated ac current of each converter limb (rms): 10A;

Floating capacitors (C): $560 \mu \mathrm{F}$;

Number of series connected inverter modules in each phase leg (FC \& FC-H) N:2;

Number of series connected inverter modules in each phase leg (FB) N:4;

Load resistance $\left(\mathrm{R}_{\mathrm{L}}\right): 20 \Omega$;

Load inductance $\left(\mathrm{L}_{\mathrm{L}}\right): 20 \mathrm{mH}$.

(2).Parameters of the experimental MMCC system:

Modulation index (Ma): 0.8;

Valve type: Infineon IGBT;

Switching frequency (fs): $400 \mathrm{~Hz}$;

Rated DC voltage rating of each modules: $20 \mathrm{~V}$;

Rated ac current of each converter limb (rms): 10A;

Number of series connected inverter modules in each phase leg $\mathrm{N}: 2$;

Load resistance $\left(\mathrm{R}_{\mathrm{L}}\right)$ : $7.5 \Omega$;

Load inductance $\left(\mathrm{L}_{\mathrm{L}}\right): 10 \mathrm{mH}$;

\section{References}

[1] R. Marquardt, and A. Lesnicar, "A new modular voltage source inverter topology." In Power Electronics and Applications (EPE), 2003 6th European Conference on, pp. 0-55. IEEE, 2013.

[2] M. Hagiwara, and H. Akagi, "Control and experiment of pulsewidth-modulated modular multilevel converters," Power electronics, IEEE Transactions on, vol. 24, no. 7, pp. 1737-1746, 2009.

[3] P. Munch, D. Gorges, M. Izák, and S. Liu, "Integrated current control, energy control and energy balancing of modular multilevel converters." In IECON 2010-36th Annual Conference on IEEE Industrial Electronics Society, pp. 150-155. IEEE, 2010.

[4] R. Marquardt, "Modular Multilevel Converter: An universal concept for HVDC-Networks and extended DC-Bus-applications." In Power Electronics Conference (IPEC), 2010 International, pp. 502-507. IEEE, 2010.

[5] D. Siemaszko, A. Antonopoulos, K. Ilves, M. Vasiladiotis, L. Angquist, and H.-P. Nee, "Evaluation of control and modulation methods for modular multilevel converters." In Power Electronics Conference (IPEC), 2010 International, pp. 746-753. IEEE, 2010. 
[6] E. Solas, G. Abad, J. Barrena, A. Cárcar, and S. Aurtenetxea, "Modelling, simulation and control of modular multilevel converter." In Power Electronics and Motion Control Conference (EPE/PEMC), 2010 14th International, pp. T2-90. IEEE, 2010.

[7] J. Rodriguez, S. Bernet, W. Bin, J. O. Pontt, and S. Kouro, "Multilevel Voltage-Source-Converter Topologies for Industrial Medium-Voltage Drives," Industrial Electronics, IEEE Transactions on, vol. 54, no. 6, pp. 2930-2945, 2007.

[8] S. Kouro, M. Malinowski, K. Gopakumar, J. Pou, L. G. Franquelo, W. Bin, J. Rodriguez, M. A. Perez, and J. I. Leon, "Recent Advances and Industrial Applications of Multilevel Converters," Industrial Electronics, IEEE Transactions on, vol. 57, no. 8, pp. 2553-2580, 2010.

[9] B. Gemmell, J. Dorn, D. Retzmann, and D. Soerangr, "Prospects of multilevel VSC technologies for power transmission." In Transmission and Distribution Conference and Exposition, 2008. T\&D. IEEE/PES, pp. 1-16. IEEE, 2008.

[10] S. Kouro, M. Malinowski, K. Gopakumar, J. Pou, L. G. Franquelo, B. Wu, J. Rodriguez, M. A. Perez, and J. I. Leon, "Recent Advances and Industrial Applications of Multilevel Converters," Industrial Electronics, IEEE Transactions on, vol. 57, no. 8, pp. 2553-2580, 2010.

[11] A. Lesnicar, and R. Marquardt, "An innovative modular multilevel converter topology suitable for a wide power range." In Power Tech Conference Proceedings, 2003 IEEE Bologna, vol. 3, pp. 6-pp. IEEE, 2003.

[12] Siemens. "SINAMICS GM150 - The universal drive solution for single drives in the medium voltage," http://www.industry.siemens.com/drives/global/en/converter/mv-drives/sinamics-gm150/.

[13] M. A. Perez, S. Bernet, J. Rodriguez, S. Kouro, and R. Lizana, "Circuit Topologies, Modeling, Control Schemes, and Applications of Modular Multilevel Converters," Power Electronics, IEEE Transactions on, vol. 30, no. 1, pp. 4-17, 2015.

[14] L. Xiaoqian, S. Qiang, L. Wenhua, R. Hong, X. Shukai, and L. Licheng, "Protection of Nonpermanent Faults on DC Overhead Lines in MMC-Based HVDC Systems," Power Delivery, IEEE Transactions on, vol. 28 , no. 1, pp. 483-490, 2013.

[15] J. Zhang, and C. Zhao, "The Research of SM Topology With DC Fault Tolerance in MMC-HVDC," Power Delivery, IEEE Transactions on, vol. 30, no. 3, pp. 1561-1568, 2015.

[16] E. Solas, G. Abad, J. A. Barrena, S. Aurtenetxea, A. Carcar, and L. Zajac, "Modular Multilevel Converter With Different Submodule Concepts;Part II: Experimental Validation and Comparison for HVDC Application," Industrial Electronics, IEEE Transactions on, vol. 60, no. 10, pp. 4536-4545, 2013.

[17] A. Nami, L. Jiaqi, F. Dijkhuizen, and G. D. Demetriades, "Modular Multilevel Converters for HVDC Applications: Review on Converter Cells and Functionalities," Power Electronics, IEEE Transactions on, vol. 30, no. 1, pp. 18-36, 2015.

[18] I. B. Efika, C. J. Nwobu, and L. Zhang, "Reactive power compensation by modular multilevel flying capacitor converter-based STATCOM using PS-PWM." 7th IET International Conference on Power Electronics, Machines and Drives (PEMD 2014) pp. 1-6, 2014.

[19] I. B. Efika, L. Zhang, A. Watson, and J. Clare, "An overlapping multi-hexagon space vector modulation scheme for modular multilevel cascade converters." In Power Electronics and Applications (EPE), 2013 15th European Conference on, pp. 1-11. IEEE, 2013.

[20] H. S. Patel, and R. G. Hoft, "Generalized Techniques of Harmonic Elimination and Voltage Control in Thyristor Inverters: Part II---Voltage Control Techniques," Industry Applications, IEEE Transactions on, no. 5, pp. 666-673, 1974.

[21] H. S. Patel, and R. G. Hoft, "Generalized techniques of harmonic elimination and voltage control in thyristor inverters: Part I--Harmonic Elimination," Industry Applications, IEEE Transactions on, no. 3, pp. 310-317, 1973.

[22] L. Li, D. Czarkowski, Y. Liu, and P. Pillay, "Multilevel selective harmonic elimination PWM technique in series-connected voltage inverters," Industry Applications, IEEE Transactions on, vol. 36, no. 1, pp. 160-170, 2000.

[23] S. Sirisukprasert, J.-S. Lai, and T.-H. Liu, "Optimum harmonic reduction with a wide range of modulation indexes for multilevel converters," Industrial Electronics, IEEE Transactions on, vol. 49, no. 4, pp. 875-881, 2002.

[24] B. Velaerts, P. Mathys, E. Tatakis, and G. Bingen, "A novel approach to the generation and optimization of three-level PWM wave forms for induction motor inverters." In Power Electronics Specialists Conference, 1988. PESC'88 Record, 19th Annual IEEE, pp. 1255-1262. IEEE, 1988.

[25] L. M. Tolbert, and T. G. Habetler, "Novel multilevel inverter carrier-based PWM method," Industry Applications, IEEE Transactions on, vol. 35, no. 5, pp. 1098-1107, 1999.

[26] V. G. Agelidis, and M. Calais, "Application specific harmonic performance evaluation of multicarrier PWM techniques." In Power Electronics Specialists Conference, 1998. PESC 98 Record. 29th Annual IEEE, vol. 1, pp. 172-178. IEEE, 1998. 
[27] B. P. McGrath, and D. G. Holmes, "A comparison of multicarrier PWM strategies for cascaded and neutral point clamped multilevel inverters." In Power Electronics Specialists Conference, 2000. PESC 00. 2000 IEEE 31st Annual, vol. 2, pp. 674-679. IEEE, 2000.

[28] V. R. Stefanovic, and S. N. Vukosavic, "Space-vector PWM voltage control with optimized switching strategy." In Industry Applications Society Annual Meeting, 1992, Conference Record of the 1992 IEEE, pp. 1025-1033. IEEE, 1992.

[29] D. Peng, F. C. Lee, and D. Boroyevich, "A novel SVM algorithm for multilevel three-phase converters." In Power Electronics Specialists Conference, 2002. Pesc 02. 2002 IEEE 33rd Annual, vol. 2, pp. 509513. IEEE, 2002.

[30] J. H. Seo, C. H. Choi, and D.-S. Hyun, "A new simplified space-vector PWM method for three-level inverters," Power Electronics, IEEE Transactions on, vol. 16, no. 4, pp. 545-550, 2001.

[31] G. Brando, A. Dannier, A. Del Pizzo, and D. Iannuzzi, "A SVM technique with homopolar voltage control in m-level multi modular converters." In Power Engineering, Energy and Electrical Drives (POWERENG), 2013 Fourth International Conference on, pp. 1531-1537. IEEE, 2013.

[32] Q. A. Le, and D. C. Lee, "Reduction of Common-Mode Voltages for Five-Level Active NPC Inverters by the Space-Vector Modulation Technique," IEEE Transactions on Industry Applications, vol. 53, no. 2, pp. 1289-1299, 2017.

[33] F. Rojas, R. Cárdenas, R. Kennel, J. C. Clare, and M. Díaz, "A Simplified Space-Vector Modulation Algorithm for Four-Leg NPC Converters," IEEE Transactions on Power Electronics, vol. 32, no. 11, pp. 8371-8380, 2017.

[34] J. Wang, Y. Gao, and J. Weidong, “A Carrier-Based Implementation of Virtual Space Vector Modulation for Neutral Point Clamped Three-Level Inverter," IEEE Transactions on Industrial Electronics, vol. PP, no. 99, pp. 1-1, 2017.

[35] L. Tan, B. Wu, V. K. Sood, D. Xu, M. Narimani, Z. Cheng, and N. R. Zargari, "A Simplified Space Vector Modulation for Four-Level Nested Neutral-Point Clamped Inverters with Complete Control of Flying-Capacitor Voltages," IEEE Transactions on Power Electronics, vol. PP, no. 99, pp. 1-1, 2017.

[36] F. B. Grigoletto, M. Stefanello, G. S. d. Silva, and H. Pinheiro, "Space vector pulse width modulation for Modular Multilevel Converters." In Industrial Electronics Society, IECON 2016-42nd Annual Conference of the IEEE, pp. 2575-2581. IEEE, 2016.

[37] B. Sirisha, and P. S. Kumar, "A simplified space vector PWM for cascaded H-Bridge inverter including over modulation operation." In India Conference (INDICON), 2016 IEEE Annual, pp. 1-6. IEEE, 2016.

[38] I. Ahmed, V. B. Borghate, A. Matsa, P. M. Meshram, H. M. Suryawanshi, and M. A. Chaudhari, "Simplified space vector modulation techniques for multilevel inverters," IEEE Transactions on Power Electronics, vol. 31, no. 12, pp. 8483-8499, 2016.

[39] Y. Deng, Y. Wang, K. H. Teo, M. Saeedifard, and R. G. Harley, "Optimized Control of the Modular Multilevel Converter Based on Space Vector Modulation," IEEE Transactions on Power Electronics, 2017.

[40] H. Zhang, W. Liu, Z. Chen, G. Luo, J. Liu, and D. Zhao, "Asymmetric Space Vector Modulation for PMSM Sensorless Drives based on Square-Wave Voltage Injection Method," IEEE Transactions on Industry Applications, 2017.

[41] S. Zhao, X. Huang, Y. Fang, and J. Zhang, "Compensation of DC-link Voltage Fluctuation for Railway Traction PMSM in Multiple Low Switching Frequency Synchronous Space Vector Modulation Modes," IEEE Transactions on Vehicular Technology, 2017.

[42] K. Pratheesh, G. Jagadanand, and R. Ramchand, "A Generalized Switch Matrix Based Space Vector Modulation Technique using Nearest Level Modulation Concept for Neutral Point Clamped Multilevel Inverters," IEEE Transactions on Industrial Electronics, 2017.

[43] H. Akagi, "Classification, Terminology, and Application of the Modular Multilevel Cascade Converter (MMCC)," Power Electronics, IEEE Transactions on, vol. 26, no. 11, pp. 3119-3130, 2011.

[44] Z. Lim, A. I. Maswood, and G. H. P. Ooi, "Modular-Cell Inverter Employing Reduced Flying Capacitors With Hybrid Phase-Shifted Carrier Phase-Disposition PWM," Industrial Electronics, IEEE Transactions on, vol. 62, no. 7, pp. 4086-4095, 2015.

[45] V. Dargahi, A. K. Sadigh, M. Abarzadeh, S. Eskandari, and K. A. Corzine, "A New Family of Modular Multilevel Converter Based on Modified Flying-Capacitor Multicell Converters," Power Electronics, IEEE Transactions on, vol. 30, no. 1, pp. 138-147, 2015.

[46] D. G. Holmes, and T. A. Lipo, Pulse width modulation for power converters: principles and practice: John Wiley \& Sons, 2003.

[47] S. Digital, “eZdsp F28335 Technical Reference," Spectrum Digital Incorporated, 2007. 